\title{
Coupled atmosphere-ocean-wave simulations of a storm event over the Gulf of Lion and Balearic Sea
}

\author{
Lionel Renault, ${ }^{1}$ Jacopo Chiggiato, ${ }^{2,3}$ John C. Warner, ${ }^{4}$ Marta Gomez, ${ }^{5}$ Guillermo Vizoso, ${ }^{6}$ \\ and Joaquin Tintoré ${ }^{1,6}$ \\ Received 9 February 2012; revised 25 July 2012; accepted 7 August 2012; published 15 September 2012.
}

[1] The coastal areas of the North-Western Mediterranean Sea are one of the most challenging places for ocean forecasting. This region is exposed to severe storms events that are of short duration. During these events, significant air-sea interactions, strong winds and large sea-state can have catastrophic consequences in the coastal areas. To investigate these air-sea interactions and the oceanic response to such events, we implemented the Coupled Ocean-Atmosphere-Wave-Sediment Transport Modeling System simulating a severe storm in the Mediterranean Sea that occurred in May 2010. During this event, wind speed reached up to $25 \mathrm{~m} . \mathrm{s}^{-1}$ inducing significant sea surface cooling (up to $2^{\circ} \mathrm{C}$ ) over the Gulf of Lion $(\mathrm{GoL})$ and along the storm track, and generating surface waves with a significant height of $6 \mathrm{~m}$. It is shown that the event, associated with a cyclogenesis between the Balearic Islands and the GoL, is relatively well reproduced by the coupled system. A surface heat budget analysis showed that ocean vertical mixing was a major contributor to the cooling tendency along the storm track and in the GoL where turbulent heat fluxes also played an important role. Sensitivity experiments on the ocean-atmosphere coupling suggested that the coupled system is sensitive to the momentum flux parameterization as well as air-sea and air-wave coupling. Comparisons with available atmospheric and oceanic observations showed that the use of the fully coupled system provides the most skillful simulation, illustrating the benefit of using a fully coupled ocean-atmosphere-wave model for the assessment of these storm events.

Citation: Renault, L., J. Chiggiato, J. C. Warner, M. Gomez, G. Vizoso, and J. Tintoré (2012), Coupled atmosphere-ocean-wave simulations of a storm event over the Gulf of Lion and Balearic Sea, J. Geophys. Res., 117, C09019, doi:10.1029/2012JC007924.

\section{Introduction}

[2] The Gulf of Lion (GoL) and the Balearic Sea (BS) in the northwestern Mediterranean are characterized by the occurrence of intense air-sea interactions. Surrounding mountains ranges (Sistema Iberíco, Pyrenees, Massif Central and Alps, see Figure 1) strongly influence the coastal meteorology of the region, inducing the presence of low level, cold air outbreaks associated with Mistral, Tramontane and Cierzo winds [e.g., Jansá, 1987; Flamant, 2003] (Figure 1). These winds are frequently observed to extend several hundreds of kilometers from the coast [Jansá, 1987], bringing cold and dry

\footnotetext{
${ }^{1}$ ICTS SOCIB, Palma de Mallorca, Spain.

${ }^{2}$ Undersea Research Centre, NATO, La Spezia, Italy.

${ }^{3}$ Now at ISMAR, Consiglio Nazionale delle Ricerche, Venice, Italy.

${ }^{4}$ Coastal and Marine Geology Program, U.S. Geological Survey, Woods Hole, Massachusetts, USA.

${ }^{5}$ Puertos del Estado, Madrid, Spain.

${ }^{6}$ IMEDEA, UIB-CSIC, Esporles, Spain.

Corresponding author: L. Renault, ICTS SOCIB, Parc Bit, Naorte, Bloc A $2^{\circ}$ p. pta. 3, Palma de Mallorca ES-07121, Spain. (lrenault@imedea.uib-csic.es)

Published in 2012 by the American Geophysical Union.
}

continental air over the warm western Mediterranean often reaching the North African coasts and as far as the Ionian Sea and hence generating intense heat air-sea exchanges [Flamant, 2003; Lebeaupin Brossier and Drobinski, 2009] and sea surface cooling [Millot, 1979; Estournel et al., 2003].

[3] These winds are mainly caused by large differences between a high pressure between Spain and the southeast of France and a low pressure over the GoL or Gulf of Genoa. The high frequency and intensity of these winds is a direct consequence of the frequency and intensity of these Mediterranean cyclones [Lionello et al., 2002]. Cyclogenesis is dependent on the season [Trigo et al., 1999; Campins et al., 2000; Buzzi and Speranza, 1986; Lionello et al., 2006] and, as suggested by Jansá et al. [1994] and Alpert and Ziv [1989], is sustained and intensified by latent heat flux and air-sea temperature contrast. Low pressure systems can then travel from the Iberian Catalan coast to the Balearic Islands and turn on the GoL where they generate or induce intense local acceleration [Campins et al., 1995] of the Mistral and Tramontane winds and enhance the air-sea interactions.

[4] The general oceanic surface circulation of the GoL and BS is characterized by the presence of the Northern Current (Figure 1) flowing southwestward along the continental 


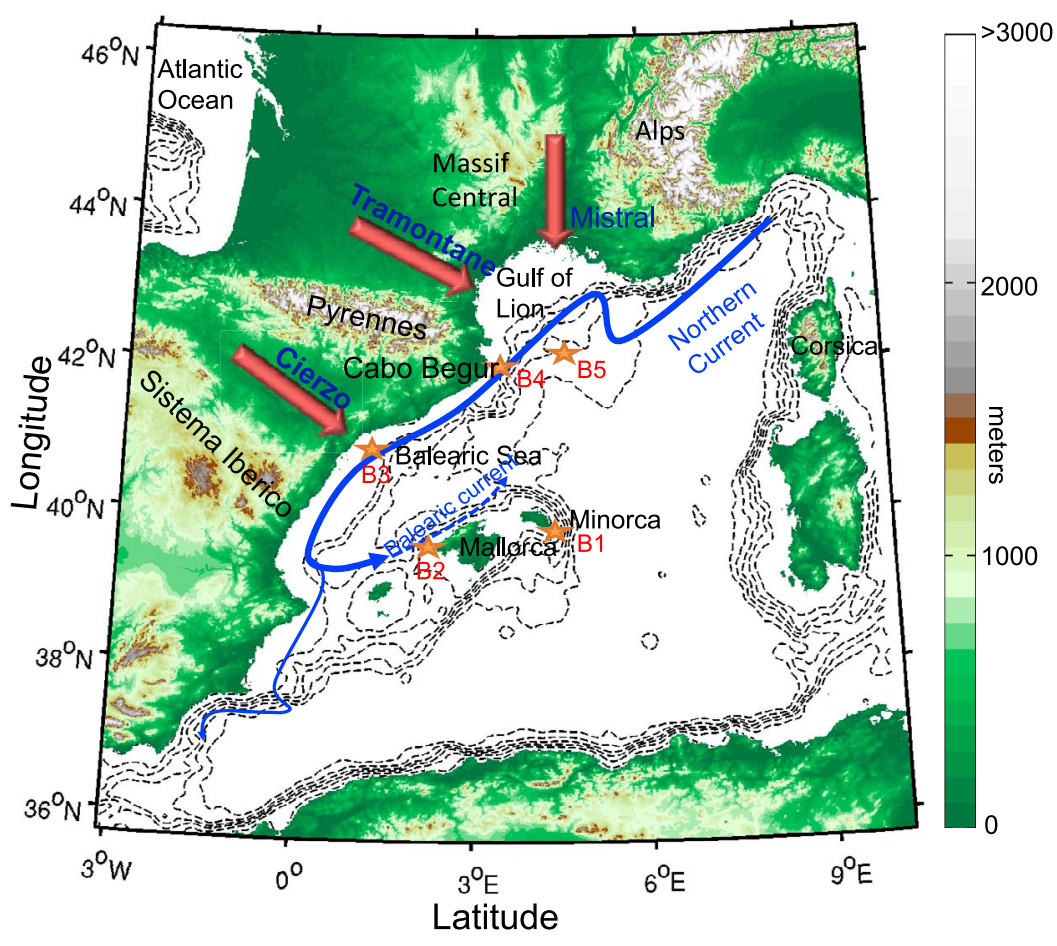

Figure 1. Main characteristic of the studied zone. Color fields represent the land topography (in meters) and dashed contours the bathymetry (in meters, contours every $500 \mathrm{~m}$ ). The main winds are indicated by red arrows and the main oceanic currents are indicated by the blue vectors. Orange stars indicate the in situ buoy location.

slope until it either exits the basin through the Ibiza Channel or retroflects cyclonically over the insular slope forming, together with the inflow of more recent Atlantic water, the Balearic Current (Figure 1) [Font et al., 1988; Font, 1990; Pinot et al., 1994; Onken et al., 2008]. Observations of the seasonal frequency of the Northern Current [Béthoux, 1980; Font et al., 1988] reveal higher transports in winter than in summer (1.5-2 Sv and $1 \mathrm{~Sv}$, respectively), while the opposite is found in the Balearic Current $(0.3 \mathrm{~Sv}$ in winter compared with $0.6 \mathrm{~Sv}$ in summer). The general circulation is also marked by the Catalan front that separates the saltier old Atlantic water in the central part from fresher shelf waters near the Catalan coast.

[5] Air-sea interactions and their impact on the general circulation of the Mediterranean Sea are not well known and therefore are very difficult to parametrize in numerical models. In previous studies, high-resolution ocean-atmosphere coupled models were implemented over the Mediterranean Sea to investigate air-sea interactions during extreme weather conditions. Pullen et al. [2003, 2006, 2007], using the Coupled Ocean Atmosphere Mesoscale Prediction System (COAMPS) model, showed the atmosphere-ocean two-way coupling significantly improved their model performances in simulating Bora winds in the Northern Adriatic reducing the mean bias of wind speed and Sea Surface Temperature (SST) against observations with respect to one-way coupling. During two Mistral/Tramontane events, Lebeaupin Brossier and Drobinski [2009] carried out a slab ocean model (simple ocean model that describes the ocean as a motionless layer of water of fixed depth) coupled with an atmospheric model. They identified the processes involved in the ocean mixed layer response and pointed out the importance to develop a full coupling ocean-atmosphere model to understand the air-sea interactions present during such wind events. Small et al. [2011] assessed in the Ligurian Sea the air-sea coupling using the COAMPS model simulations and in situ observations. They showed that taking into account SST feedback to the atmosphere reduces biases in latent heat flux. Katsafados et al. [2011] investigated the sensitivity of a storm event in the Mediterranean Sea to different SST sources. Main results indicated that surface fluxes had a weak impact on the location and intensity of the studied storm.

[6] Several studies have shown the relevance of atmospherewave coupling for storm-surge modeling [Mastenbroek et al., 1993], weather and wave prediction [Doyle, 1995; Janssen et al., 2002, 2004; Janssen, 2004; Lionello et al., 2003 ] and ocean circulation and variabililty [Burgers et al., 1995]. These studies show that atmosphere-wave coupled models improve the representation of the momentum flux and then the realism of the simulations. In particular, Janssen et al. [2002] demonstrated that by modifying the Charnock relation to take the wave age dependence into account, both atmospheric circulation and wavefield representation were improved. A severe storm event associated with a cyclogenesis in the GoL and BS that occurred in May 2010 is analyzed here using the fully Coupled Ocean Atmosphere Wave Sediment Transport (COAWST) model [Warner et al., 2010]. The main objective is to understand the atmospherewave-ocean interactions involved during such an event and how coupled models can improve the realism of simulations 
with respect to uncoupled models. In this sense, the present work is an extension of the former studies by, e.g., Pullen et al. [2007] or Lebeaupin Brossier and Drobinski [2009]. The main motivations are: (1) to evaluate the performance of the fully ocean-atmosphere-wave coupled model during the event; (2) to understand the oceanic-atmospheric-wave interactions to increase the capability to predict extreme weather conditions and consequences; (3) to assess the driving mechanisms that control the oceanic and wave response to extreme weather in the western Mediterranean Sea and their sensitivity to the ocean-atmosphere-wave feedback.

[7] The paper is organized as follows: Section 2 provides a description of the data used and an overview of the scene from the observations. Section 3 describes the models used as well as the different experiments carried out. In section 4, the simulations are evaluated with respect to the observations during the specific storm event, allowing an in-depth description of the storm and the mechanisms responsible for the cooling of the surface ocean mixed layer. Finally, section 5 assesses the sensitivity of the models to the different way of coupling. Our results are then discussed in section 6, which is followed by the conclusions. A list of acronyms used throughout the paper is provided in Appendix A.

\section{Data Description and Overview of the Storm}

\subsection{Data}

[8] Several routinely available data sets of observations have been collected to assess the realism and to evaluate the performance of the simulations during this specific storm event.

\subsubsection{Meteo-Oceanographic Buoys}

[9] In situ data have been collected from a total of 5 meteooceanographic buoys (locations are shown in Figure 1). Four buoys belong to the Puertos del Estado (Spain) deep-sea network [Alvarez-Fanjul et al., 2003], located where the water column is at least $200 \mathrm{~m}$ deep. In details, these four buoys are located close to Mahon $\left(39.72^{\circ} \mathrm{N}-4.44^{\circ} \mathrm{E}, \mathrm{B} 1\right)$, Dragonera $\left(39.55^{\circ} \mathrm{N}-2.10^{\circ} \mathrm{E}, \mathrm{B} 2\right)$, Tarragona $\left(40.68^{\circ} \mathrm{N}-\right.$ $1.47^{\circ} \mathrm{E}, \mathrm{B} 3$ ) and Cabo Begur (hereinafter $\mathrm{CB}, 41.92^{\circ} \mathrm{N}-$ $\left.3.65^{\circ} \mathrm{E}, \mathrm{B} 4\right)$. Depending on the buoy, $2 \mathrm{~m}$ air temperature (T2m), $3 \mathrm{~m}$ wind speed, mean sea level pressure (MSLP), significant wave height (Hsig), wave peak period (Tp) and temperature at $1 \mathrm{~m}$ depth are routinely measured. Wind speed from the buoys was adjusted to the reference height of $10 \mathrm{~m}$ using the Large and Pond [1981] algorithm. An additional fifth buoy is located in the GoL $\left(42.1^{\circ} \mathrm{N}-4.7^{\circ} \mathrm{E}\right.$, B5 on Figure 1) and managed by Météo France. This buoy (hereinafter GL, B5) routinely provides all the parameters cited above expect that the wave period measured is the wave period of the highest one-third of the waves (T1/3). In an area such as the Mediterranean Sea, both quantities will be quite similar, yet $\mathrm{T} 1 / 3$ is generally lower than $\mathrm{Tp}(\mathrm{T} 1 / 3 \sim 0.95 \mathrm{Tp})$. Nevertheless, for clarity, in this study, the GoL measured wave period will be called Tp as the others buoys. Additionally, the measured wind is adjusted by Météo France at $10 \mathrm{~m}$. Note the buoys measure the ocean temperature at about $1 \mathrm{~m}$ depth, then, when comparing with the model SST, this difference in definition might result in small systematic differences. Finally, in this study, the bias is defined as the difference between model and observation; thus a positive bias means simulations overestimate a quantity.

\subsubsection{Cloud Cover From Meteosat Visible Images}

[10] The geostationary Meteosat satellites constantly observe the same region of the Earth and monitor cloud patterns and other weather phenomena. Three channels are available: in the solar spectrum (VISible, VIS) between 0.4 and $1.1 \mu \mathrm{m}$, in the IR window region between 10.5 and $12.5 \mu \mathrm{m}$, and in the WV absorption band between 5.7 and $7.1 \mu \mathrm{m}$. In this study, only the VIS images, characterized by a spatial resolution of $2.5 \mathrm{~km} \times 2.5 \mathrm{~km}$, are used.

\subsubsection{ASCAT Wind}

[11] The last generation scatterometer Advanced SCATterometer (ASCAT) [Bartalis et al., 2007] onboard MetOp-A satellite provides surface wind speed and direction over global ocean with a spatial resolution of $25 \mathrm{~km}^{2}$ over two swaths of $550 \mathrm{~km}$ widths. Comparisons between ASCAT and various buoys indicated the root-mean squared differences of the wind speed and direction are $1.72 \mathrm{~m} . \mathrm{s}^{-1}$ and 18 degrees respectively. For higher wind conditions, ASCAT is biased slightly low [Bentamy et al., 2008].

\subsubsection{SST Products From Remote Sensing}

[12] MODIS L3 product (http://oceandata.sci.gsfc.nasa. gov) provided daily SST with a spatial resolution of $\sim 4 \mathrm{~km}$. However, the use of an optimally interpolated data set was necessary because of the almost fully overcast conditions during the storm. This complementary SST product is the Delayed Time Gruppo di Oceanografia da Satellite (GOS) Interpolated SST L4 Analysis provided at a resolution of $1 / 16^{\circ}$. Validation shows the stddev is generally below $0.5^{\circ} \mathrm{K}$ and the mean error is around $0.1^{\circ} \mathrm{K}$ (B. Nardelli, personal communication, 2012, and http://projets.ifremer.fr/cersat/ Data/Quality-control/MyOcean-SST-QC/Control-ValidationMyOcean/).

\subsubsection{FNL Analysis}

[13] The initial and boundary conditions of the atmospheric model were derived from the National Centers for Environmental Prediction (NCEP) Final Analyses (FNL, http://dss.ucar.edu/datasets/ds083.2) and have a spatial resolution of $1^{\circ}$ and a temporal resolution of $6 \mathrm{~h}$.

\subsection{Overview of the Storm}

[14] As illustrated in Figure 2a by the MSLP from the FNL analysis, a cyclogenesis is initiated over the Balearic Sea around 1800 UTC 03 May 2010 and is associated with a drop in mean sea level of several $\mathrm{hPa}$ in a few hours (not shown). The low pressure intensifies while moving to the north-northwest of the GoL. Then, after reaching the French coast, it moves southeast while collapsing (not shown). This is confirmed by Figures $2 \mathrm{~b}$ and $2 \mathrm{c}$ that show the visible satellite images at 0600 UTC and 1200 UTC 04 May 2010. The visible channel exhibits a rounded and clear-eye cloud structure traveling toward the GoL.

[15] MSLP and $10 \mathrm{~m}$ wind in situ measurement at CB and GL buoys confirm the presence of the storm (Figure 3a). MSLP sharply decreases from $1010 \mathrm{hPa}$ to $993 \mathrm{hPa}$ in a few hours, whereas wind is intensified up to $25 \mathrm{~m} . \mathrm{s}^{-1}$. A closer inspection of the wind intensity and direction from in situ data at GL and CB buoys indicates that, before the storm, the wind regime at $10 \mathrm{~m}$ over the GoL is characterized by two non-stationary converging flows: Tramontane wind and Mistral wind (see Figures 1 and $3 \mathrm{~b}$ ). After a few hours, at 0600 UTC 04 May 2010, the northward displacement of the low pressure blocked the Mistral and the Tramontane 

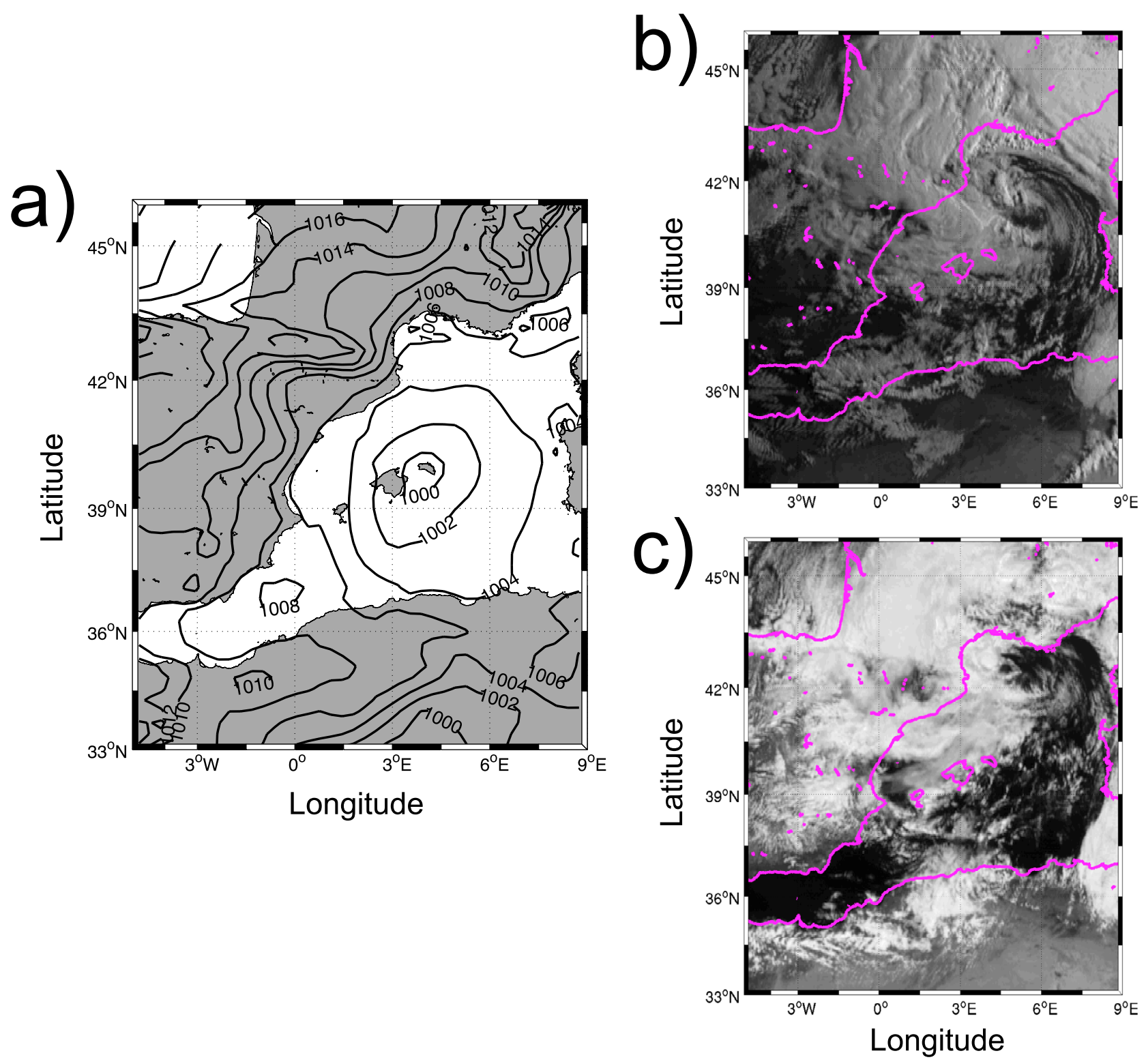

Figure 2. (a) Mean sea level pressure at 1800 UTC 03 May 2010 from FNL analysis. Visible image (b) on 0600 UTC 04 May 2010 and (c) on 1200 UTC 04 May 2010.

prevails (Figures $3 \mathrm{a}$ and $3 \mathrm{~b}$ ), peaking up to $25 \mathrm{~m} \cdot \mathrm{s}^{-1}$ and sharply decreasing a few hours later. Wind speed measurements by ASCAT at 0842 UTC 04 May 2010 confirms the presence of the clear-eye and the intensification of the Tramontane wind reaching up to $25 \mathrm{~m} . \mathrm{s}^{-1}$ and blowing over the Balearic Sea (Figure 4a). Finally, in situ measurments of $\mathrm{T} 2 \mathrm{~m}$ at GL buoy reveal a significant decrease of $\mathrm{T} 2 \mathrm{~m}$ from $\sim 15^{\circ} \mathrm{C}$ to $9^{\circ} \mathrm{C}$ (Figure $3 \mathrm{c}$ ), as these winds are advecting cold continental air.

[16] As suggested by in situ measurements of SST at CB and GL buoys (Figure 3c), the Mistral and Tramontane intensifications enhance air-sea interactions and induce a cooling of the ocean upper layer. SST drops by $1.5^{\circ} \mathrm{C}$ in a few hours during the storm. The SST L4 analysis, due to the almost fully overcast conditions during the storm, is affected by a cold bias with respect the in situ observations before the storm and a warm bias at the end of the storm, therefore underestimating the cooling of SST (Figures 3c, 4b, and 4c). Nevertheless, it indicates that the maximum cooling is situated in the area of direct influence of the Tramontane intensification (Figures $4 \mathrm{~b}$ and $4 \mathrm{c}$ ). Last, as illustrated in Figure $3 \mathrm{~d}$, the sustained Tramontane generates waves with significant wave height of $5.5 \mathrm{~m}$ at GL and CB buoys with peak period of $9 \mathrm{~s}$.

\section{Model and Experiments Description}

[17] The Coupled Ocean-Atmosphere-Wave-SedimentTransport (COAWST) Modeling System [Warner et al., 2010] is comprised of several components that include models for the ocean (Regional Ocean Modeling System, ROMS), atmosphere (Weather and Research Forecasting model, WRF), surface waves (Simulating WAves Nearshore, SWAN), a coupler to exchange data fields (The Model 
Cabo Begur

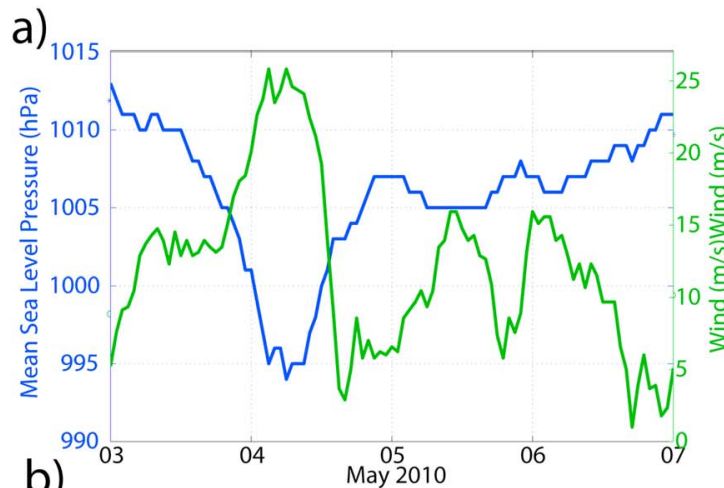

b)
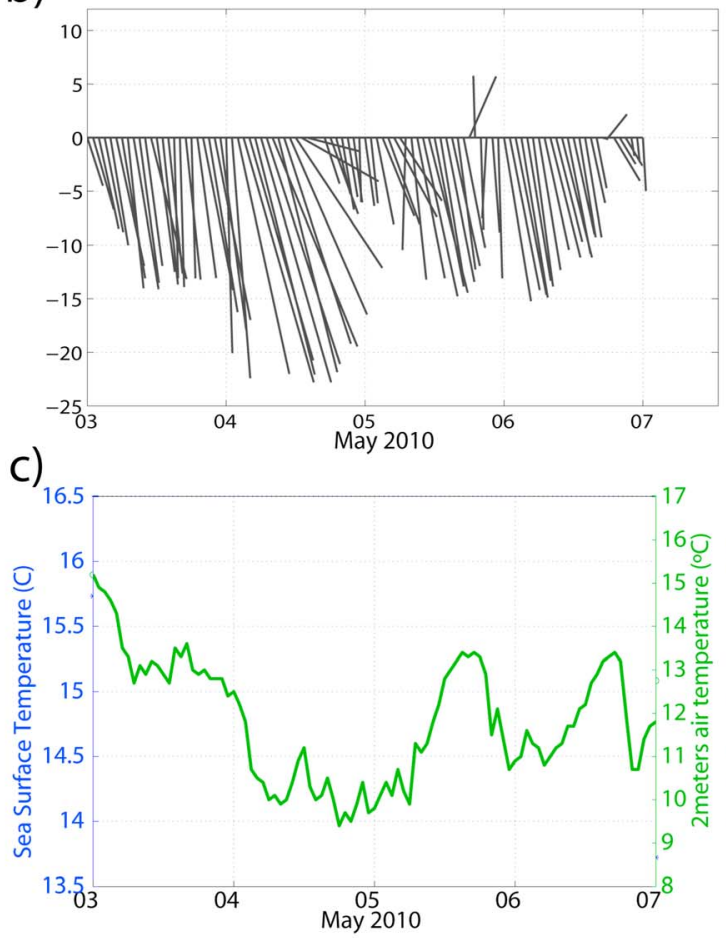

d)

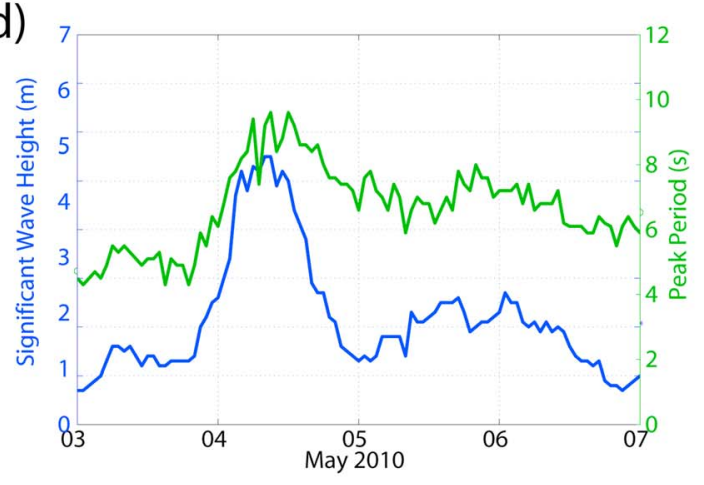

Gulf of Lion
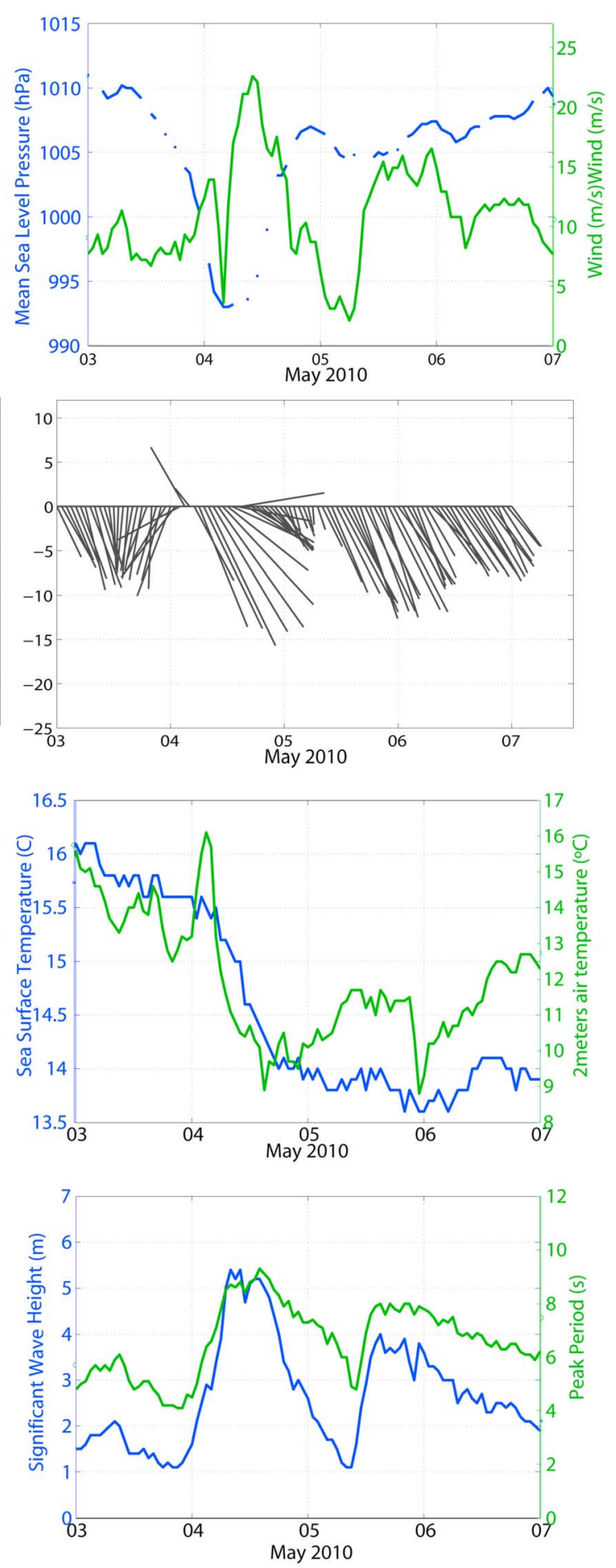

Figure 3. Time series of the main atmospheric and oceanic sea surface variables. (a) The green and blue lines represent the wind speed and the Mean sea level pressure as observed at the Cabo Begur and Gulf of Lion buoys. (b) The $10 \mathrm{~m}$ wind (m.s ${ }^{-1}$ ) at Cabo Begur and Gulf of Lion buoys. (c) The blue and green lines represent the sea surface temperature and $2 \mathrm{~ms}$ air temperature observed at the Cabo Begur and Gulf of Lion buoys (if available). (d) The blue and the green lines represent the significant wave height and the peak period as observed at the Cabo Begur and Gulf of Lion buoys. 

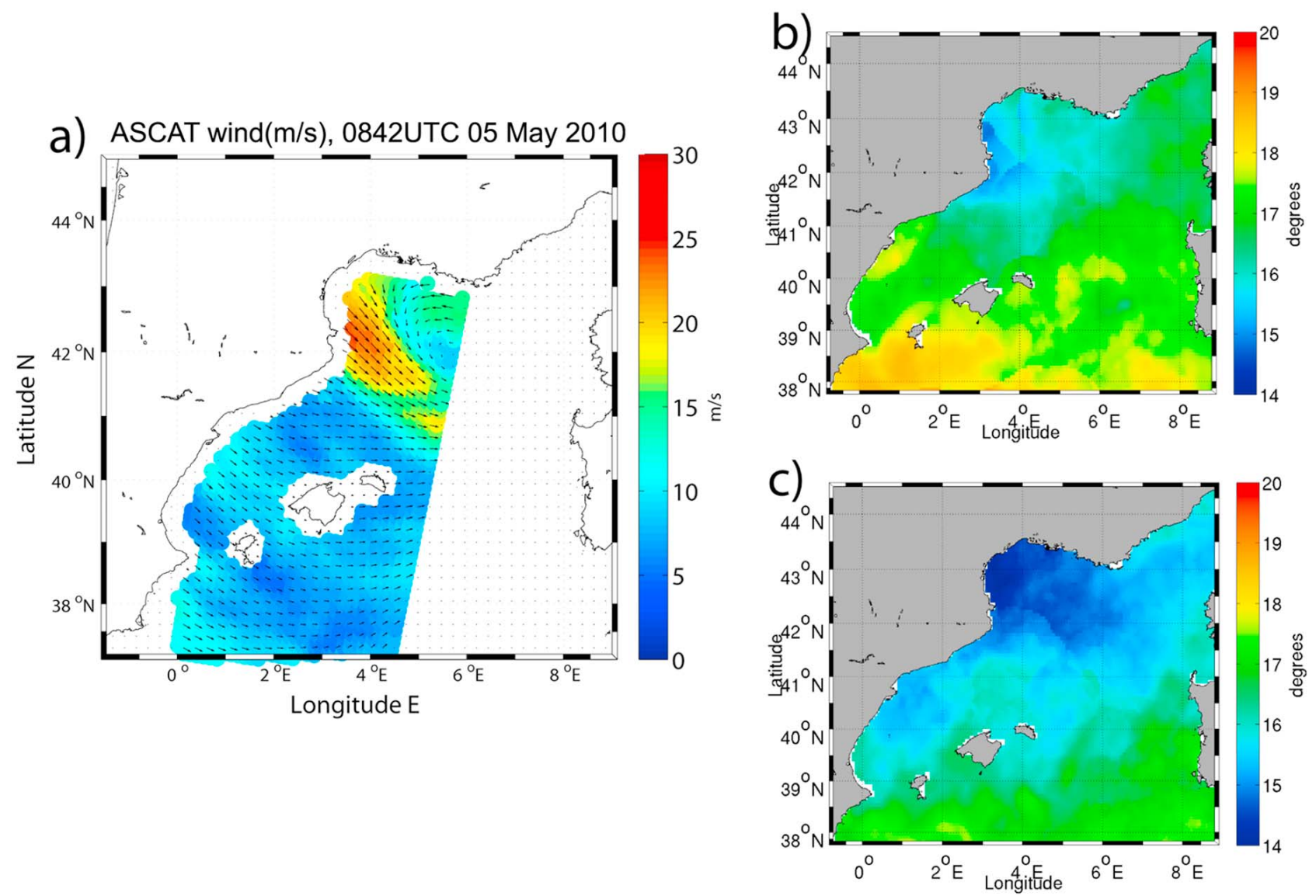

Figure 4. (a) Wind snapshot, 0842 UTC 04 May 2010 as observed by ASCAT. The color fields represent the wind speed intensity $(\mathrm{m} / \mathrm{s})$ and the arrows the wind speed direction. Sea surface temperature from L4 SST product (b) before the storm (0000 UTC 03 May 2010) and (c) after the storm (0000 UTC 07 May 2010).

Coupling Toolkit, MCT) and a method for regridding (Spherical Coordinate Remapping Interpolation Package, SCRIP). A description of how each model was configured for this study and the different kinds of experiment carried out are given below. The reader is referred to Warner et al. [2008a, 2010] for detailed descriptions of the coupling methodology.

\subsection{Atmospheric Model}

[18] The Weather Research and Forecasting (WRF) model (v3.0) [Skamarock and Klemp, 2007] has been first applied in a 3 nested grids configuration (Figure 5). The largest domain (WRF1) covers approximately the western Mediterranean basin with a horizontal resolution of $27 \mathrm{~km}$. The second domain (WRF2) covers the area that corresponds approximately to the region included between the Alborán Sea and Corsica with a horizontal resolution of $9 \mathrm{~km}$ (Figure 5a). The coarser WRF1 grid reproduces the large scale synoptic features that force the local dynamics in the second WRF2 grid at each time step. Simulations are performed using a two-way nesting technique, starting at 0000 UTC 01 May 2010 and lasting 6 days. Forty-six levels in the vertical are stretched to provide higher vertical resolution in the lower levels. These two domains are initialized from the FNL Analyses and the lateral boundary conditions of the coarser grid (WRF1) are prescribed by the same analysis every $6 \mathrm{~h}$. This configuration was spun up first for two days using as a surface forcing the FNL SST avoiding model drift. The four last days are simulated in forecast mode without SST update.

[19] The third WRF domain (WRF3) covers the region from Corsica to the Spanish west coast peninsula (Figure 5b). The horizontal resolution is $3 \mathrm{~km}$ and is discretized with 46 vertical levels. The simulation was spun up for one day starting from the WRF2 simulation output fields at 0000 UTC 02 May 2010. Boundary conditions every hour are prescribed from the WRF2 simulation using the NDOWN tools [Skamarock et al., 2008]. Only this third domain is eventually coupled with ROMS and SWAN.

[20] The following parameterization schemes were used in all the simulations: the WRF SM5-class microphysics scheme [Hong et al., 2004]; the Kain Fritsch [Kain, 2004] cumulus parameterization on the coarser grids (implicit on the inner grid) and the Mellor Yamada Janjic Surface (MYJSFC) [Janjic, 2002] Planetary Boundary Layer scheme. Since the sea-state has an important impact on the air-sea momentum flux [e.g., Donelan, 1990; Johnson et al., 1998; Drennan et al., 2003; Janssen, 2004], the MYJSFC WRF scheme was modified in COAWST using the Drennan et al. [2005] parameterization for the computation of the sea-state dependent surface roughness. 


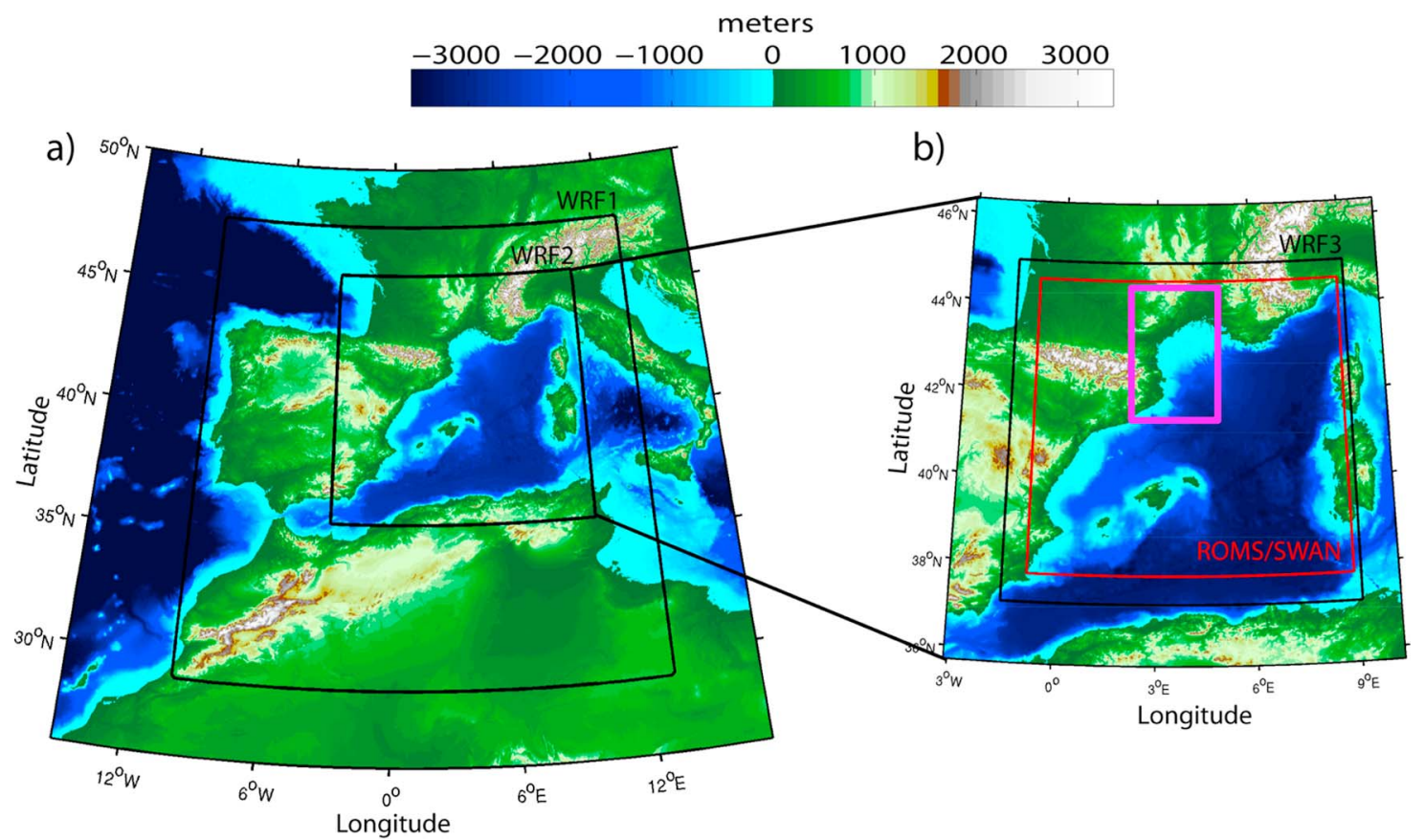

Figure 5. Domains configuration and topography of the region. (a) The WRF1 (27 km) and WRF2 $(9 \mathrm{~km})$ domains. (b) The COAWST configuration: the black and red boxes represent the WRF3 $(4.5 \mathrm{~km})$ and ROMS-SWAN domains configuration respectively (see text). Pink box represents the GoL box used in Figures 12 and $15\left(2^{\circ} \mathrm{E}-5^{\circ} \mathrm{E}-41.5^{\circ} \mathrm{N}-44^{\circ} \mathrm{N}\right)$.

\subsection{Ocean Model}

[21] ROMS (http://www.myroms.org) [Shchepetkin and McWilliams, 2005] is a 3D, free-surface, split-explicit primitive equation ocean model with Boussinesq and hydrostatic approximation. The domain (Figure 5b) covers approximately the WRF3 domain with a horizontal resolution of $\sim 1.8 \mathrm{~km}$ and 30 vertical $\sigma$-levels. Bottom topography is derived from the Smith and Sandwell product [Smith and Sandwell, 1997]. A 20 days long spin-up simulation was carried out using the atmospheric forcing derived from the HIgh Resolution Limited Area Model (Hirlam) [Unden et al., 2002] outputs provided by the Agencia Estatal de METeorología (AEMET) with a spatial resolution of $7 \mathrm{~km}$ and a temporal resolution of $3 \mathrm{~h}$. The daily Mediterranean Forecasting System (MFS) fields [Oddo et al., 2009] were used as initial and boundary conditions. The COAWST simulation was initialized from this spin-up simulation at 0000 UTC 03 May 2010.

[22] Advection for momentum is integrated using a third order upstream scheme [Shchepetkin and McWilliams, 1998], while advection for tracers is integrated using a MPDATA family scheme [Margolin and Smolarkiewicz, 1998]. The pressure gradient term is solved by a density Jacobian with cubic polynomial fits [Shchepetkin and McWilliams, 2003]. Parameterization of the ocean vertical mixing follows the generic length scale approach [Umlauf and Burchard, 2003], with "gen" closure coded in ROMS as described by Warner et al. [2005]. Open boundary conditions are applied to tracers and baroclinic velocity using a combination of Orlanskitype radiation conditions and nudging [Marchesiello et al., 2001] to MFS daily fields. The free surface and depthintegrated velocity boundary conditions are applied at the open boundary following Flather [1976] also come from MFS fields. The bottom stress is estimated by a quadratic bottom friction.

\subsection{Wave Model}

[23] The wave model employed is the Simulating WAves Nearshore (SWAN) Booij et al. [1999]. It was set-up on the same domain as ROMS (Figure 5b) and previously spin up starting from 0000 UTC 29 April 2010. It was forced by Hirlam wind [Unden et al., 2002] provided by AEMET, which have a spatial resolution of $7 \mathrm{~km}$ and a temporal resolution of $3 \mathrm{~h}$. The model was run in third-generation mode, with exponential wind growth following Snyder et al. [1981], modified by Komen et al. [1984] with white-capping formulation parameters following Rogers et al. [2003], quadruplet wave-wave interactions solved using the Discrete Interaction Approximation [Hasselmann et al., 1985] and Madsen et al. [1988] bottom friction. Waves on the boundary conditions are specified with a full two-dimensional spectra as defined from outputs of the Mediterranean simulations of the wave forecasting system developed by Puertos del Estado [Gómez Lahoz and Carretero Albiach, 2005]. This global model, based on a configuration of the WAve prediction Model (WAM) model (the WAMDI group 1988), has a spatial resolution of $5^{\prime}$ and a temporal resolution of $1 \mathrm{~h}$. This system is driven by the Hirlam wind fields supplied by AEMET [Unden et al., 2002]. The verification of the Puertos del Estado forecast system compares the model output with buoy data and shows a good agreement for the Mediterranean Sea with correlations of 0.8 , scatter index of 0.3 and mean bias lower than $0.2 \mathrm{~m}$ [Gómez Lahoz and Carretero Albiach, 2005] (also the Wave Forecast Verification Project at http:// www.jcomm.info). 


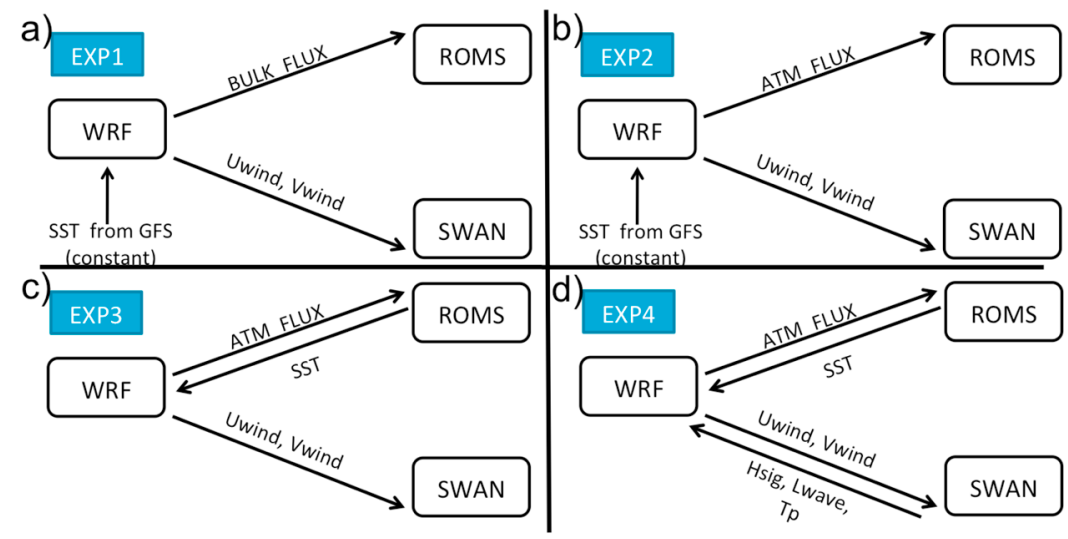

Figure 6. Scheme of the COAWST experiments. The arrows represent the coupling way with the name of the exchanged variables. BULK FLUX and ATM_FLUX are the flux parameterization defined in section 3.4. Following the considered coupling, the $10 \mathrm{~m}$ zonal and meridional wind speed (Uwind and Vwind), sea surface temperature (SST), significant wave height (Hsig), peak wavelength (Lwave) and wave peak period $(\mathrm{Tp})$ are exchanged.

\subsection{Model Coupler}

[24] The COAWST modeling system was designed to run as a single executable with each model component running on its own set of processors. At a user defined synchronization interval, the MCT [Larson et al., 2005; Warner et al., 2008a] protocols are utilized to provide efficient exchange of data fields between the various model components. If the models are on different grids, then SCRIP provides precomputed regridding weights used by MCT. We currently use a first order flux-conservative remapping scheme in the data exchange.

\subsection{Heat and Momentum Flux Parameterizations}

[25] The main differences among the numerical experiments carried out (listed and detailed in the next sub-section) are explained in terms of parameterizations of air-sea interactions and the inclusion or non inclusion of the feedback between models. Wave-current interactions (e.g., the vortexforce term as in Olabarrieta et al. [2011], the injection of turbulent kinetic energy from breaking waves as in Carniel et al. [2009], the nonlinear wave-current bottom boundary layer as in Warner et al. [2008b], the impact of surface currents on waves) may have a non-neglible impact on the ocean vertical mixing, mixed layer depth, currents and significant wave height [e.g., Qiao et al., 2006; Babanin, 2011]. The inclusion of these feedbacks requires further testing of the coupled system and additional suitable observations data set and thus are not considered in this study but left to complementary research efforts.

\subsubsection{Parameterization in the Atmospheric Component (WRF)}

[26] For the numerical simulations the WRF model was configured to compute turbulent fluxes using the MYJSFC scheme [Janjic, 2002]. The SST used to compute the stability of the surface layer can be from either the FNL global analyses or from the ROMS ocean model, depending on the selected coupling methodology. When WRF is coupled twoway with the wave model SWAN, the aerodynamic roughness length used in the computation of turbulent fluxes in
WRF is considered a function of the wave age following Drennan et al. [2005], i.e., function of the sea-state conditions.

\subsubsection{Parameterization in the Ocean Component (ROMS)}

[27] Air-sea interactions in ROMS are computed using two different approaches. In one case, ROMS receives the surface atmospheric fields (T2m, $10 \mathrm{~m}$ wind, MSLP, $2 \mathrm{~m}$ relative humidity) from WRF and computes turbulent fluxes using its own SST and the COARE 3.0 algorithm [Fairall et al., 2003]. This option is hereinafter referred to as BULK FLUX. As a second option, ROMS receives heat fluxes and momentum flux computed by WRF (hereinafter referred as ATM_FLUX). The first approach does not guarantee consistent momentum and heat flux exchanges between the atmosphere and the ocean, because each model computes turbulent flux values using different parameterizations. The second approach assures flux consistency.

\subsection{Description of the Experiments}

[28] As illustrated on Figure 6 a set of four experiments was carried out to assess the atmosphere-ocean-wave models coupling impact in simulating the selected storm event. All the experiments started from a previous common restart (see sections 3.1, 3.2 and 3.3) at 0000 UTC 03 May 2010 and were integrated for 4 days.

[29] EXP1: This is a one-way coupling experiment. ROMS is forced by the surface atmospheric fields received from WRF and uses the BULK_FLUX parameterization. SWAN is forced by the WRF $10 \overline{\mathrm{m}}$ wind fields. WRF used FNL SST analysis in the initialization and then the SST is kept constant throughout the forecast. ROMS and SWAN receive WRF fields every 10 min (Figure 6a).

[30] EXP2: similar to EXP1 but the ATM_FLUX parameterization is used in ROMS, i.e., turbulent fluxes used as ROMS surface boundary conditions are computed by WRF (Figure 6b).

[31] Either EXP1 or EXP2 would be the somewhat standard operational way to run each model considered here. 

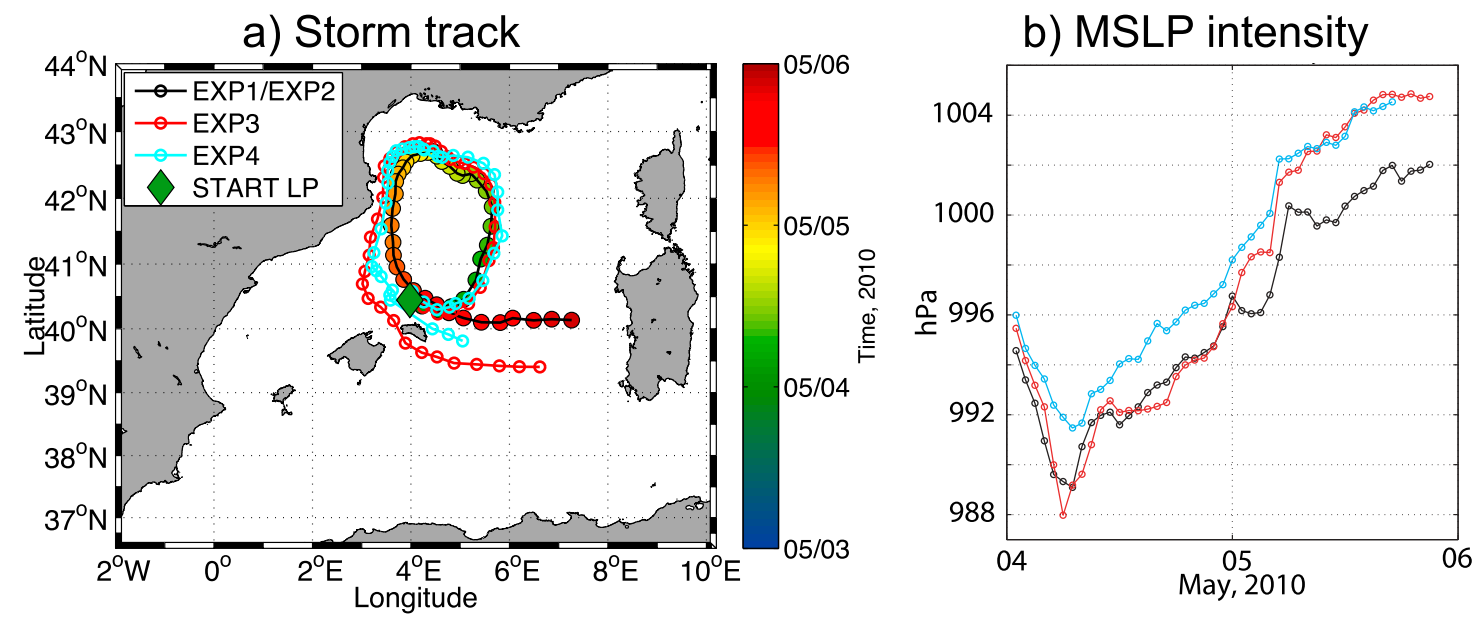

Figure 7. (a) Sensitivity of the storm track to the coupling. The black line with the colors represents the EXP1/EXP2 track and the associated time. The red and cyan lines represent the EXP3 and EXP4 respectively. The green diamond indicates the starting point of the low pressure. (b) Mean sea level pressure intensity along the track. The black, red and cyan lines represent the EXP1/EXP2, EXP3 and EXP4 respectively.

[32] EXP3: Atmosphere-Ocean two-way coupling experiment. Similar to EXP2 but WRF here receives and updates the SST every 10 min from ROMS (Figure 6c).

[33] EXP4: Atmosphere-Ocean and Atmosphere-Wave two-way coupled experiments. Similar to EXP3, except that WRF uses SWAN wave data to estimate the aerodynamic roughness (Figure 6d).

[34] ROMS and SWAN are not directly coupled in any of the experiments.

\section{Model Results}

[35] This section aims to evaluate the simulations and to complete the description of the storm and its associated oceanic response. The EXP1 is used as a benchmark since it represents a classic one-way experiment. The main findings of this section are twofold: (1) although the control run is able to reproduce reasonably the studied storm, it nevertheless overestimates the wind speed as well as the significant wave height and (2) the oceanic response is mainly driven by ocean vertical mixing and turbulent heat fluxes.

\subsection{The Simulated Storm by EXP1}

[36] In this subsection, EXP1 is evaluated with respect to the observations and allows completing the storm description and the oceanic associated response provided in section 2 . Despite some biases in terms of wind speed intensity and storm location, inducing an overestimation of Hsig and likely a too strong deepening of mixed layer, EXP1 is able to reproduce the main features of the storm event.

[37] Figure 7 shows the simulated storm track and its intensity as detected by the TRACK algorithm detection software [Hodges, 1994]. Consistent with the observations (see Figure 2), EXP1 simulated the development of a cyclogenesis around 1800 UTC 03 May 2010 that traveled from the Balearic Sea to the GoL. The low pressure intensifies down to $991 \mathrm{hPa}$ (Figure 7b) while moving to the northnorthwest between 0000 UTC and 1800 UTC 04 May 2010 and reaches the French coast around 1800 UTC 4 May 2010. Then, it veers southeast while decreasing its intensity and collapses at around 1200 UTC-1800 UTC 05 May 2010 (Figure 7a). Simulated MSLP time series have been compared on Figure 8a with available observations (see also Table 1). Although EXP1 simulates relatively well the MSLP drop monitored by the $\mathrm{CB}$ and GL buoys, it presents a mean bias of roughly $-1 \mathrm{hPa}$ and did not capture well the MSLP rebound (Figure 8a).

[38] As illustrated in Figure $8 \mathrm{~b}$ at Cabo Begur, the associated wind regime at $10 \mathrm{~m}$ over the GoL described in section 2 is relatively well reproduced by EXP1. In particular, the intensification of the Tramontane wind, as monitored by $\mathrm{CB}$ buoy, is reproduced by EXP1 but with an overestimation of the wind speed of $5 \mathrm{~m} . \mathrm{s}^{-1}$ during the peak of the storm (Figure $8 \mathrm{~b}$ and Table 2, similar results are obtained at the GL buoy) and a mean positive bias of $4 \mathrm{~m} . \mathrm{s}^{-1}$ in $\mathrm{CB}, 3 \mathrm{~m} . \mathrm{s}^{-1}$ at Tarragona and $1.8 \mathrm{~m} . \mathrm{s}^{-1}$ at GL buoy. This is confirmed by comparing ASCAT satellite measurement to the EXP1 atmospheric simulation co-located spatially and temporally (Figures 9a and 4a). EXP1 shows some slight inaccuracies in terms of geographical distribution (Gulf of Lion and Ebro area) and overestimates the strength. Finally, the atmospheric model reproduced the advection of cold continental air with decrease of $2 \mathrm{~m}$ air temperature by $3^{\circ} \mathrm{C}$ but shows a mean bias of $\sim 1^{\circ} \mathrm{C}$ and a maximum bias of $\sim 3^{\circ} \mathrm{C}$ (Table 3 and Figure $8 \mathrm{c}$ ).

[39] EXP1 simulates relatively well the observed cooling of the SST and its temporal evolution (Figure 10a), as indicated also by the small Root Mean Square Error (RMSE) and high correlation (Table 4). Mean biases, rather small, are eventually positive, which should mean that modeled SST is, on the average, warmer during the event and this suggests that the storm-induced cooling observed at the buoys is underestimated by the experiment. Figure 11 illustrates the SST cooling as simulated by EXP1 by displaying corresponding snapshots of the simulated SST. At 0000 UTC 03 May 2010 (not shown), the GoL was characterized by a 

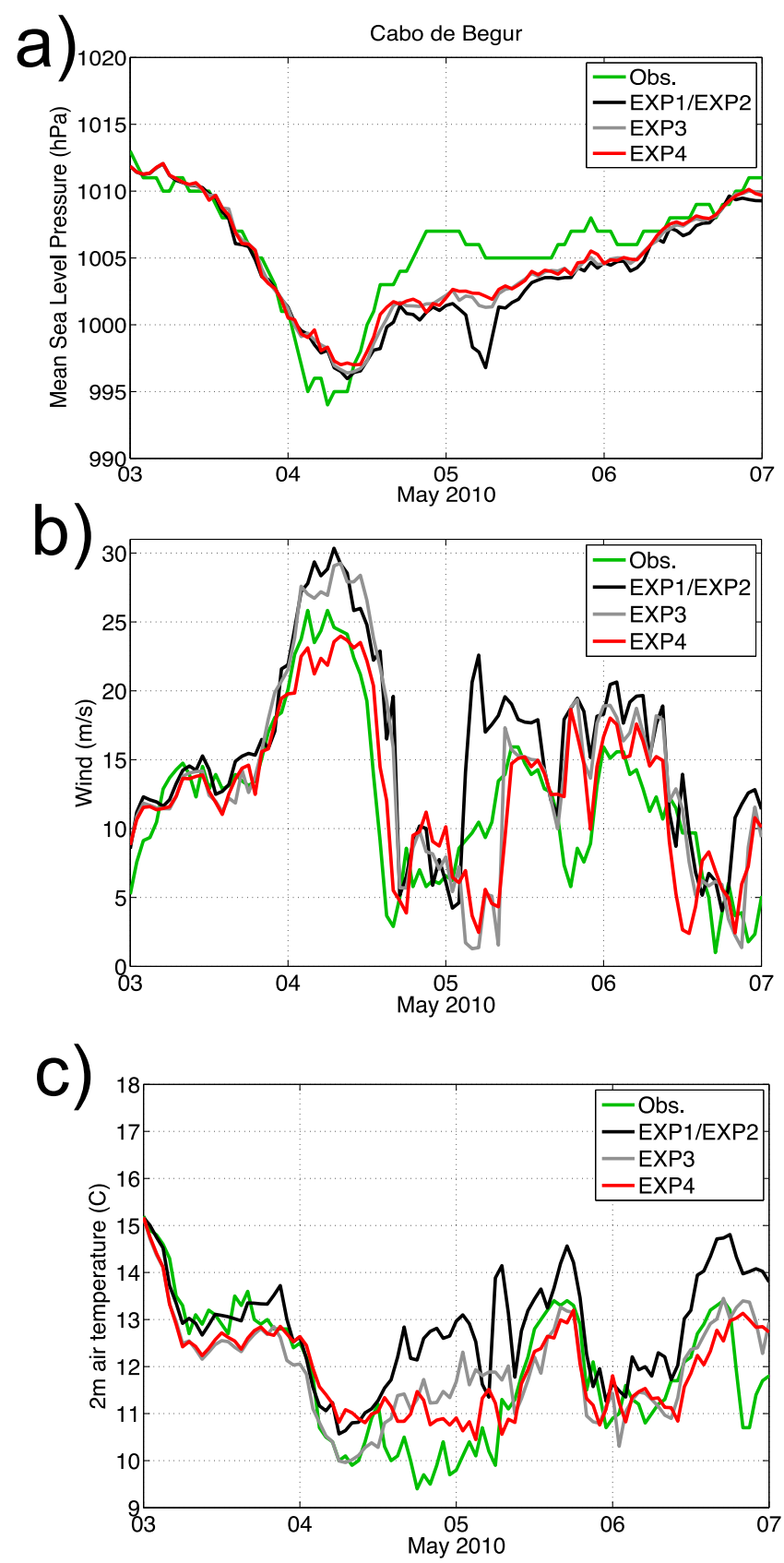

Figure 8. (a) Mean sea level pressure at Cabo Begur. The green, black, gray and red lines represent the observations, EXP1/EXP2, EXP3 and EXP4 respectively. (b) Same as Figure 8a but for the $10 \mathrm{~m}$ wind speed. (c) Same as Figure 8a but for the $2 \mathrm{~m}$ air temperature.

SST around $15^{\circ} \mathrm{C}$. As described in section 2, between 1800 UTC 03 May 2010 and 1800 UTC 04 May 2010, the simulated SST over the GoL decreased abruptly from $15.5^{\circ} \mathrm{C}$ to $14^{\circ} \mathrm{C}$ and to $13^{\circ} \mathrm{C}$ close to the GoL west coast (Figures 10a and 11). Between 0600 UTC 04 May 2010 and 0600 UTC 05 May 2010, the simulated SST decreased by $1{ }^{\circ} \mathrm{C}$ in the BS. Note, at the end of the storm, EXP1 is biased warm with respect to the GL buoy $\left(\sim 0.2^{\circ}\right.$, Figure 10a), which means the simulation likely underestimated by $\sim 0.4^{\circ} \mathrm{C}$ the storm induced SST cooling over the GoL.
Table 1. Statistics Between Model and Available In Situ Observations of MSLP From 03 May 2010 to 07 May 2010a

\begin{tabular}{|c|c|c|c|c|c|c|c|c|c|}
\hline \multirow[b]{2}{*}{ MSLP } & \multicolumn{3}{|c|}{$\begin{array}{c}\text { Cabo Begur } \\
\text { (97 Observations) }\end{array}$} & \multicolumn{3}{|c|}{$\begin{array}{c}\text { Mahon } \\
\text { (97 Observations) }\end{array}$} & \multicolumn{3}{|c|}{$\begin{array}{c}\text { Gulf of Lion } \\
\text { (75 Observations) }\end{array}$} \\
\hline & MB & RMSE & $\mathrm{R}$ & MB & RMSE & $\mathrm{R}$ & MB & RMSE & $\mathrm{R}$ \\
\hline Exp1/Exp2 & -1.60 & 2.92 & 0.84 & -1.03 & 2.36 & 0.87 & -0.89 & 3.84 & 0.68 \\
\hline Exp3 & -1.09 & 2.26 & 0.89 & -0.76 & 2.07 & 0.90 & -0.46 & 3.60 & 0.69 \\
\hline Exp4 & -0.97 & 2.17 & 0.89 & -0.67 & 2.15 & 0.89 & -0.34 & 3.49 & 0.70 \\
\hline
\end{tabular}

${ }^{\mathrm{a}} \mathrm{MB}$ is the Mean Bias, RMSE the Root Mean Square Error and R the correlation.

However, at Dragonera, as illustrated by the Table 4, EXP1 shows a mean cold bias with respect to the observations, which means that EXP1 simulates here an excessive cooling.

[40] The EXP1 ocean model component allows characterizing the oceanic dynamical response to the storm. At the beginning of the simulation and until 1800 UTC 03 May 2010, the Northern Current is flowing southwestward along the continental slope with an intensity of $0.7 \mathrm{~m} . \mathrm{s}^{-1}$ at the surface near Cabo Begur (Figure 11a). Then until 1800 UTC 04 May 2010 (Figures $11 \mathrm{~b}$ and 11c), the Mistral triggered an intensification of the Northern Current which peaks to $1.2 \mathrm{~m} . \mathrm{s}^{-1}$ alongshore near Cabo Begur and becomes broader. At the end of the storm, its speed relaxes down to the prestorm value of $0.7 \mathrm{~m} \cdot \mathrm{s}^{-1}$ (not shown). The intensification of the wind drives a deepening of the Mixed Layer Depth (MLD). From less than $40 \mathrm{~m}$, simulated Mixed Layer (ML) deepens down to $120 \mathrm{~m}$ (Figure 11) over the Tramontane wind intensification zone. Unfortunaly, during this event, there is no MLD in situ data available. Last, the overestimation of the $10 \mathrm{~m}$ wind speed in EXP1 leads to an overestimation Hsig by $2 \mathrm{~m}$ and of Tp by $2 \mathrm{~s}$ at GL buoy during the storm peak (Figures 10b and 10c). However, as specified in section 2.1 , one can note that the measured wave period at GL is the T1/3 and not the Tp, it might partly explain the differences between model and observations.

\subsection{Cooling Processes}

[41] We now investigate the mechanisms by which the storm impacted the ocean and led to the localized cooling of SST described previously. To this end, an offline mixed layer heat budget (see section A1) was considered over the storm time window. This heat budget analysis shows that the ocean vertical mixing and the turbulent heat fluxes are the main factors responsible for the cooling.

[42] The total heat loss estimated by EXP1, averaged over the GoL box (see Figure $5 \mathrm{~b}$ ), is $-1211 \mathrm{~W} / \mathrm{m}^{2}$ with maximum heat loss of about $-4500 \mathrm{~W} / \mathrm{m}^{2}$ near the Spanish coast (Figures 12a and 12d). The region of maximum cooling is

Table 2. Statistics Between Model and Available In Situ Observations of $10 \mathrm{~m}$ Wind Speed From 03 May 2010 to 07 May 2010

\begin{tabular}{|c|c|c|c|c|c|c|c|c|c|}
\hline \multirow[b]{2}{*}{ Wind } & \multicolumn{3}{|c|}{$\begin{array}{c}\text { Cabo Begur } \\
\text { (97 Observations) }\end{array}$} & \multicolumn{3}{|c|}{$\begin{array}{c}\text { Tarragona } \\
\text { (97 Observations) }\end{array}$} & \multicolumn{3}{|c|}{$\begin{array}{c}\text { Gulf of Lion } \\
\text { (97 Observations) }\end{array}$} \\
\hline & MB & RMSE & $\mathrm{R}$ & MB & RMSE & $\mathrm{R}$ & MB & RMSE & $\mathrm{R}$ \\
\hline Exp1/Exp2 & 4.01 & 5.98 & 0.75 & 3.08 & 4.39 & 0.49 & 1.80 & 3.71 & 0.77 \\
\hline Exp3 & 1.82 & 4.83 & 0.78 & 2.80 & 4.32 & 0.48 & 1.12 & 4.15 & 0.70 \\
\hline Exp4 & 0.53 & 3.79 & 0.79 & 1.84 & 3.35 & 0.51 & 0.82 & 3.71 & 0.65 \\
\hline
\end{tabular}

${ }^{\mathrm{a}} \mathrm{MB}$ is the Mean Bias, RMSE the Root Mean Square Error and R the correlation. 

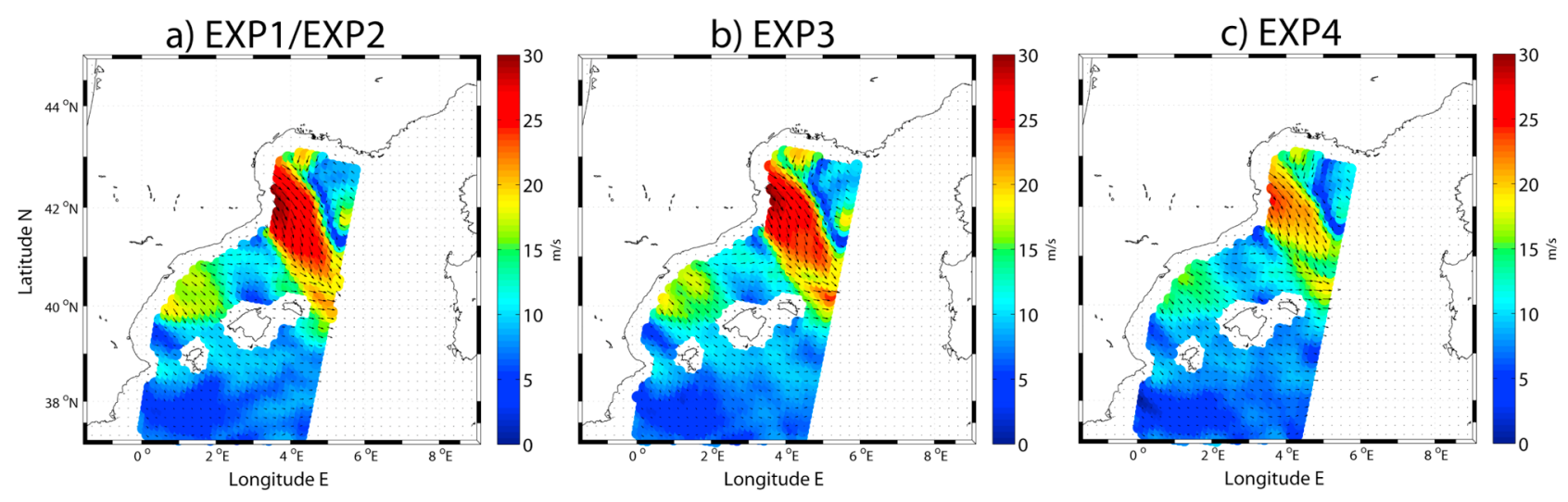

Figure 9. Wind snapshot, interpolated at 0842 UTC 04 May 2010 as simulated by (a) EXP1/EXP2, (b) EXP3 and (c) EXP4. The color fields represent the wind speed intensity $\left(\mathrm{m} . \mathrm{s}^{-1}\right)$ and the arrows the wind speed direction.

underneath local maxima of Tramontane wind during the storm. Results indicate first that, although the Northern Current increased during the storm and ML deepened, lateral advection and ML entrainment are marginal contributors to the temperature changes as they represent respectively only $-100 \mathrm{~W} / \mathrm{m}^{2}$ and $-80 \mathrm{~W} / \mathrm{m}^{2}$ (8\% and $6.7 \%$ of the cooling, Figure 12d). Overcast conditions during the storm led to limited heating by the shortwave radiation by $77 \mathrm{~W} / \mathrm{m}^{2}$ $(-6 \%$, Figure 12d) as well as limited the heat loss by the longwave radiation $\left(-27 \mathrm{~W} / \mathrm{m}^{2}, 2 \%\right.$ of the cooling over the GoL, Figure 12d).

[43] On the other hand, heat loss by latent and sensible heat fluxes was significant during the storm (respectively $-173 \mathrm{~W} / \mathrm{m}^{2}$ and $-90 \mathrm{~W} / \mathrm{m}^{2}$, see Figures $12 \mathrm{~b}$ and $12 \mathrm{~d}$ ) accounting for roughly a quarter of the total heat loss in the ML (15\% and $7.5 \%$ of the cooling) over the GoL box with peaks of total $-700 \mathrm{~W} / \mathrm{m}^{2}\left(-500 \mathrm{~W} / \mathrm{m}^{2}\right.$ and $-200 \mathrm{~W} / \mathrm{m}^{2}$ respectivelly) over the area of maximum cooling. Surface cooling by heat fluxes and evaporation during the storm increased the density of surface waters, leading to unstable conditions that in turn enhanced ocean vertical mixing. As shown in Figure 12d, the ocean vertical mixing term is the main contributor to the simulated cooling. It represents a cooling of $-820 \mathrm{~W} / \mathrm{m}^{2}(68 \%)$ over the GoL with a peak of $-3500 \mathrm{~W} / \mathrm{m}^{2}$ (77\% of the cooling) in the area of direct influence of the Tramontane wind. Along the storm track (Figure 12c), the cooling is dominated by the ocean vertical mixing term (up to $-2500 \mathrm{~W} / \mathrm{m} 2, \sim 85 \%$ of the cooling, Figure 12), with heat fluxes not intense as in the GoL box (Figure 12b). In fact, as illustrated on Figure 12c, the divergence term (mostly ocean vertical mixing, not shown) is clearly marked by the storm track. According to model results, local air-sea interactions (wind stirring and heat fluxes) were the causes of the abrupt cooling.

\section{Sensitivity of the Results}

[44] In this section, the focus is on the sensitivity of the results to the different way of coupling. The main findings show that:

[45] 1. The flux parameterizations that are based on a constant Charnock parameter (ATM_FLUX) provide lower momemtum flux and therefore, impact the ocean mixed layer deepening as well as the SST cooling.

[46] 2. Amosphere-ocean coupling weakens locally the $10 \mathrm{~m}$ wind speed and change $\mathrm{T} 2 \mathrm{~m}$, improving the simulation. The oceanic response is characterized by lower ocean vertical mixing and turbulent heat fluxes and then lower SST cooling. Nevertheless, $10 \mathrm{~m}$ wind speed and Hsig are still overestimated.

[47] 3. When coupling atmosphere to wave, the sea-state induced roughness changes the estimation of the drag coefficient and increases momentum flux. That changes the oceanic response by increasing ocean vertical mixing and then inducing a higher SST cooling that in turn, combined with the induced surface roughness, weakens the $10 \mathrm{~m}$ wind speed and then Hsig, reducing biases. This fully coupled simulation provides the best picture of the event.

\subsection{Heat and Momentum Fluxes Parameterization: EXP1 Versus EXP2}

[48] In this subsection, by comparing EXP1 to EXP2, as shown in former studies [e.g., Janssen, 2004], it is found that the flux parameterization based on a constant Charnock parameter (ATM FLUX) provides lower momemtum flux. Hence, since this last plays an important role in determining ocean vertical mixing, this last is reduced by twice. These differences impact the ML deepening as well as the SST cooling.

5.1.1. Impact on the Momentum Flux

[49] In order to illustrate the difference between EXP1 and EXP2, Figure 13 displays the time series of the $10 \mathrm{~m}$ wind

Table 3. Statistics Between Model and Available In Situ Observations of T2m From 03 May 2010 to 07 May 2010

\begin{tabular}{|c|c|c|c|c|c|c|c|c|c|}
\hline \multirow[b]{2}{*}{$\mathrm{T} 2 \mathrm{~m}$} & \multicolumn{3}{|c|}{$\begin{array}{c}\text { Cabo Begur } \\
\text { (97 Observations) }\end{array}$} & \multicolumn{3}{|c|}{$\begin{array}{c}\text { Mahon } \\
\text { (97 Observations) }\end{array}$} & \multicolumn{3}{|c|}{$\begin{array}{c}\text { Gulf of Lion } \\
\text { (97 Observations) }\end{array}$} \\
\hline & $\mathrm{MB}$ & RMSE & $\mathrm{R}$ & MB & RMSE & $\mathrm{R}$ & MB & RMSE & $\mathrm{R}$ \\
\hline Exp1/Exp2 & 1.00 & 1.46 & 0.66 & 0.74 & 1.33 & 0.86 & 1.33 & 1.74 & 0.76 \\
\hline Exp3 & 0.14 & 0.93 & 0.76 & 0.19 & 0.94 & 0.90 & 0.45 & 1.17 & 0.78 \\
\hline Exp4 & 0.12 & 0.80 & 0.84 & 0.21 & 0.83 & 0.93 & 0.47 & 1.13 & 0.82 \\
\hline
\end{tabular}

${ }^{\mathrm{a}} \mathrm{MB}$ is the Mean Bias, RMSE the Root Mean Square Error and R the correlation. 

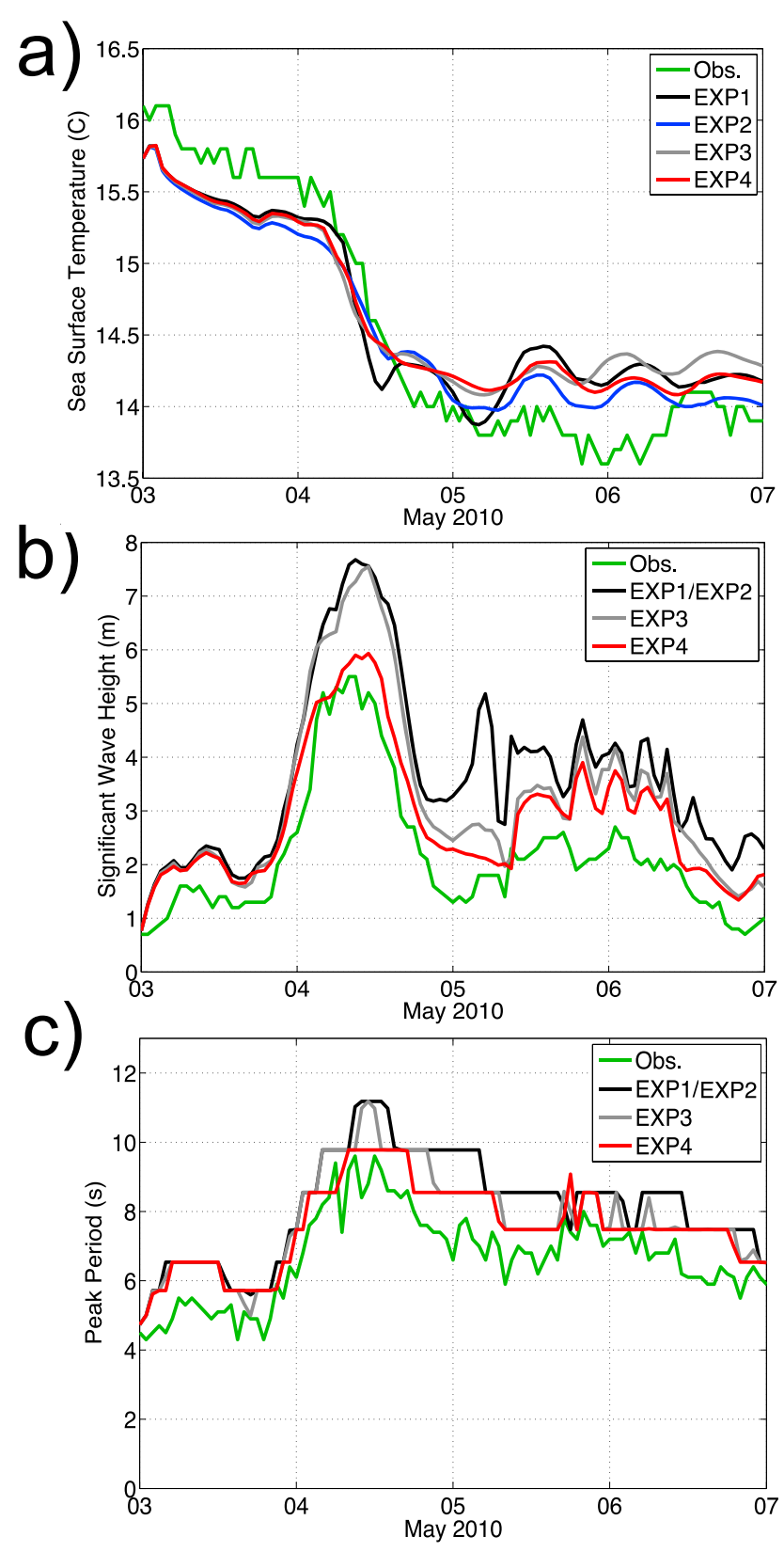

Figure 10. (a) Sea surface temperature at GoL buo. The green, black, blue, gray and red lines represent the observations, EXP1, EXP2, EXP3 and EXP4 respectively. (b) Significant wave height at GoL buoy, the green, black, gray and red lines represent the observations, EXP1/EXP2, EXP3 and EXP4 respectively. (c) Same as Figure 10b but for the wave peak period.

speed and the momentum flux at the $\mathrm{CB}$ location as estimated by the different experiments. Although EXP2 and EXP1 have identical solutions for the atmospheric component as WRF is run uncoupled, during the storm peak EXP1 momentum flux estimated in ROMS using BULK FLUX is more than twice the momentum flux estimated using ATM_FLUX in EXP2 $\left(3.2 \mathrm{~N} / \mathrm{m}^{2}\right.$ versus $\left.1.3 \mathrm{~N} / \mathrm{m}^{2}\right)$. EXP1 SST is generally colder (see Figure 14). In the computation of the momentum flux, this should mean a more stable surface atmospheric boundary layer and therefore a decrease of the momentum flux. The fact that the momentum flux computed by ROMS in EXP1 is instead higher therefore must be indirectly explained by the different parameterizations BULK_FLUX and ATM_FLUX used to compute the drag coefficient.

[50] As shown in Janssen [2004] and by recent field campaigns speeds [e.g., Edson, 2008; Yelland et al., 1998] the Charnok parameter is sea-state dependent and increases with wind speed beyond $10 \mathrm{~m} \cdot \mathrm{s}^{-1}$, so that a parameterization based on a constant Charnock [1955] or Large and Pond [1981] underestimates the drag on surface winds [Fairall et al., 2003; Janssen, 2004]. In EXP2, ATM_FLUX is based on a constant Charnock coefficient parameterization (Charnock parameter $\alpha=0.018$ ); then, during the storm peak (wind up to $30 \mathrm{~m} \cdot \mathrm{s}^{-1}$ in EXP1/EXP2), momentum flux is likely underestimated. In EXP1, BULK FLUX is based on the Fairall et al. [2003] parameterization where the original value of the Charnock parameter has been replaced by one that increases with wind speeds up to $20 \mathrm{~m} . \mathrm{s}^{-1}$. It should be noted that the validity of Fairall et al. [2003] is also questionable at wind speed well above $20 \mathrm{~m} . \mathrm{s}^{-1}$, and the extension of routinely used parameterizations to high wind speed regimes in the model is foreseen but still in progress.

\subsubsection{Impact on the Oceanic Response}

[51] The momentum flux plays an important role in determining ocean vertical mixing and turbulent heat fluxes, which in turn control the storm induced cooling of the SST (section 4.2). Thus, any changes in momentum flux can potentially impact the ocean response to the storm. To illustrate this, Figures $15 \mathrm{a}$ and $15 \mathrm{~b}$ depict the mean differences between EXP2 and EXP1 during the storm (averaged on the 04 May 2010) in terms of net heat fluxes and divergence (mainly driven by ocean vertical mixing, see section 4.2). Figure $15 \mathrm{~g}$ provides the average over the GoL Box of each term of the heat balance for each experiment. Main differences in terms of heat fluxes occur over the area where Tramontane is stronger. Heat loss by latent and sensible heat fluxes over the GoL box are respectively $-173 \mathrm{~W} / \mathrm{m}^{2}$ and $-90 \mathrm{~W} / \mathrm{m}^{2}$ in EXP1 and $-285 \mathrm{~W} / \mathrm{m}^{2}$ and $-145 \mathrm{~W} / \mathrm{m}^{2}$ in EXP2 (differences $\sim 40 \%$ in both latent and sensible), and differences in net heat fluxes can reach locally up to $500 \mathrm{~W} / \mathrm{m}^{2}$ (50\%, Figure 15a). Large ROMS momentum flux in EXP1 induces a stronger ocean vertical mixing over the GoL and overall along the storm track (Figures $15 \mathrm{~b}$ and $15 \mathrm{~g}$ ) with respect to EXP2. Indeed, cooling differences by ocean

Table 4. Statistics Between Model and Available In Situ Observations of SST From 03 May 2010 to 07 May $2010^{\mathrm{a}}$

\begin{tabular}{|c|c|c|c|c|c|c|c|c|c|}
\hline \multirow[b]{2}{*}{ SST } & \multicolumn{3}{|c|}{$\begin{array}{c}\text { Gulf of Lion } \\
\text { (97 Observations) }\end{array}$} & \multicolumn{3}{|c|}{$\begin{array}{c}\text { Tarragona } \\
\text { (97 Observations) }\end{array}$} & \multicolumn{3}{|c|}{$\begin{array}{c}\text { Dragonera } \\
\text { (97 Observations) }\end{array}$} \\
\hline & MB & RMSE & $\mathrm{R}$ & MB & RMSE & $\mathrm{R}$ & MB & RMSE & $\mathrm{R}$ \\
\hline Exp1 & 0.07 & 0.33 & 0.96 & 0.14 & 0.35 & 0.88 & -0.38 & 0.45 & 0.9 \\
\hline Exp1 WRF & 1.68 & 1.89 & 0 & 1.50 & 1.64 & 0 & 0.56 & 0.98 & 0 \\
\hline Exp2 & -0.01 & 0.29 & 0.98 & 0.35 & 0.51 & 0.83 & -0.06 & 0.27 & 0.95 \\
\hline Exp3 & 0.10 & 0.36 & 0.97 & 0.47 & 0.59 & 0.85 & -0.12 & 0.27 & 0.96 \\
\hline Exp4 & 0.07 & 0.31 & 0.98 & 0.30 & 0.43 & 0.89 & -0.26 & 0.36 & 0.95 \\
\hline
\end{tabular}

${ }^{\mathrm{a}} \mathrm{MB}$ is the Mean Bias, RMSE the Root Mean Square Error and R the correlation. 
a)

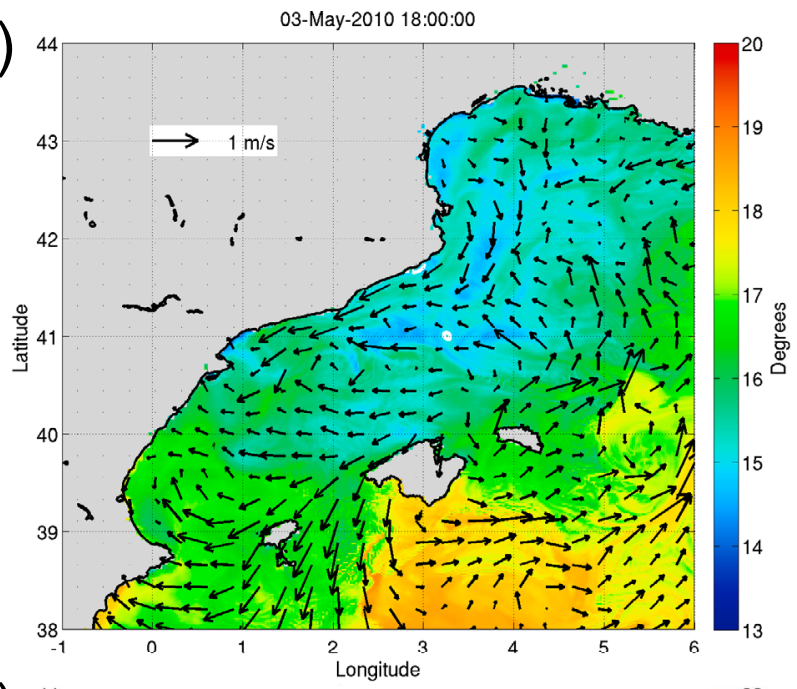

b)

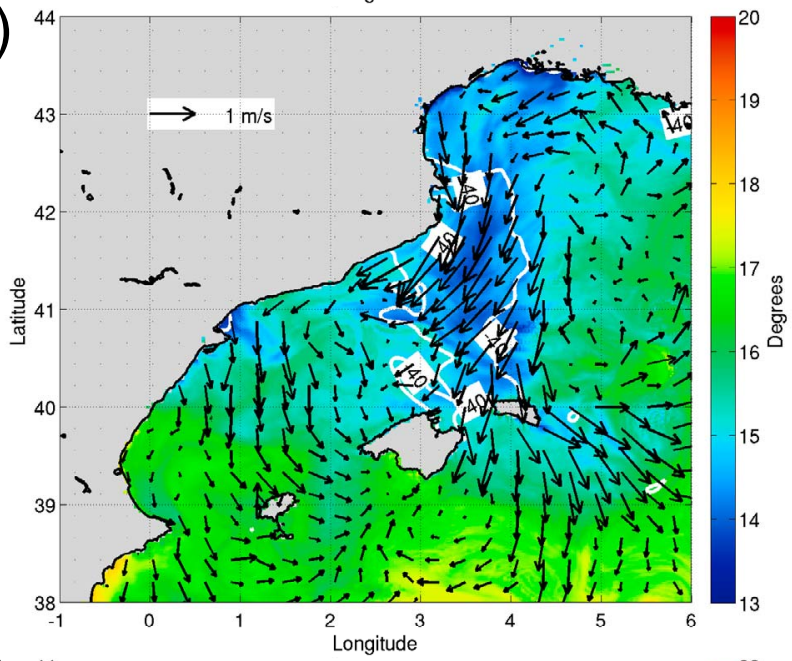

c)

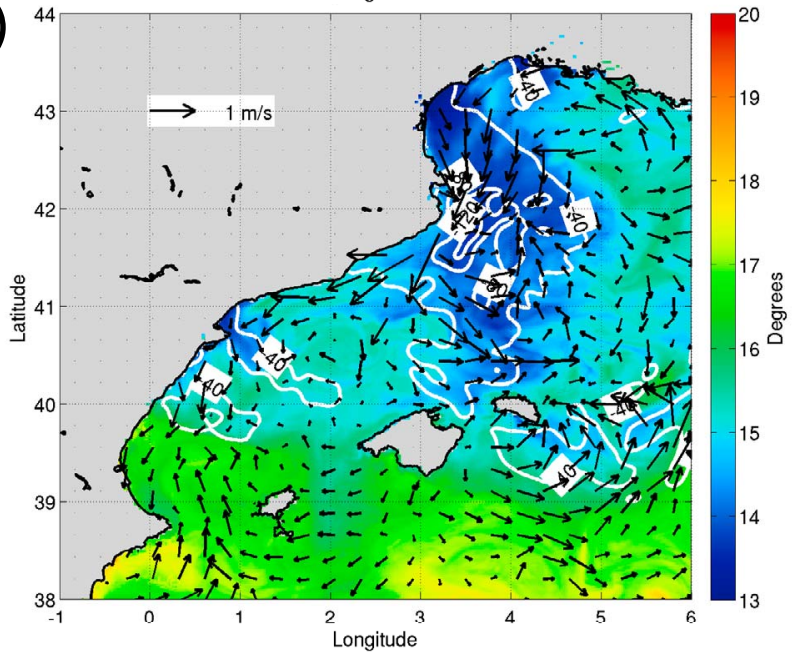

Figure 11. Oceanic snapshots every $12 \mathrm{~h}$ from the $1800 \mathrm{UTC}$ 03 May 2010 as simulated by EXP1. The color fields represent the sea surface temperature $\left({ }^{\circ} \mathrm{C}\right)$, the arrows the surface current direction and intensity $\left(\mathrm{m} . \mathrm{s}^{-1}\right)$ and the white contour the mixed layer depth (in meters, one contour each $40 \mathrm{~m}$ ). vertical mixing can reach up to $-1500 \mathrm{~W} / \mathrm{m}^{2}(150 \%$ with respect to EXP2) along the storm track. Over the GoL Box, it induces a heat loss of $815 \mathrm{~W} / \mathrm{m}^{2}$ in EXP1 compared to $440 \mathrm{~W} / \mathrm{m}^{2}$ in EXP2 (85\% with respect to EXP2). Longwave radiation flux as well as the later advection is not significantly impacted and remains a marginal contributor of the cooling. The region of maximum cooling, as in EXP1, is underneath local maxima of Tramontane wind and the storm induced cooling is driven by a combination of turbulent heat fluxes and ocean vertical mixing over the GoL and mainly ocean vertical mixing along the storm track.

[52] As a results, the parameterization BULK_FLUX (EXP1) induces generally a colder $\operatorname{SST}\left(\sim 0.5^{\circ} \mathrm{C}\right.$, Figure 14a) overall over the domain with respect to ATM_FLUX in EXP2. The major differences occur along the storm track, close to the Balearics Islands where SST differences, due to different ocean vertical mixing, can reach up to $1^{\circ} \mathrm{C}$. Nevertheless, this impact is not visible on the SST moorings. At the GL buoy, the increased ocean vertical mixing is compensated by the decreased heat fluxes. The others buoys are not located where the differences are significant. Finally, since the magnitude of wind stress controls the MLD through ocean vertical mixing, not surprisingly, EXP2 simulates a shallower ML than EXP1 by several meters $(\sim 10 \mathrm{~m})$ overall over the domain and, near Cabo Begur, by $40 \mathrm{~m}$. at the end of the storm (i.e., MLD up $80 \mathrm{~m}$. depth, Figure 14b). The intensification of the North Current is slightly reduced by $0.2 \mathrm{~m} . \mathrm{s}^{-1}$ in EXP2 and peaks to $1 \mathrm{~m} \cdot \mathrm{s}^{-1}$ alongshore near Cabo Begur.

[53] Uncoupled simulations may result in biases in the estimation of wind stress and turbulent heat fluxes, as some errors may arise from missing feedbacks between the ocean and the atmosphere. When simulating cold outbreaks, the constant SST used in the atmospheric model is eventually an unchanging reservoir of heat (fuel for the storm). In addition, as highlighted in section 4, the wind speed in EXP1/EXP2 is overestimated with respect to the observations. Such overestimation leads potentially to an overestimation of the ocean vertical mixing and a ML deepening in the ocean model.

\subsection{Atmosphere-Ocean Coupling: EXP3 Versus EXP2}

[54] We now investigate the SST feedbacks impact on the results. To this end, EXP3 is compared to EXP2 and not to EXP1 since EXP2 has the same fluxes parameterization than EXP3. To summarize, when coupling atmosphere to ocean, WRF is forced by a colder SST that stabilizes the atmospheric marine boundary layer and then weakens the $10 \mathrm{~m}$ wind speed improving its representation as well as the T2m one. It also changes slightly the storm track and intensity. The oceanic response is then characterized by lower ocean vertical mixing and turbulent heat fluxes and then lower SST cooling. Nevertheless, $10 \mathrm{~m}$ wind speed intensity and Hsig are still overestimated.

\subsubsection{Impact on the Atmospheric Fields}

[55] An indication of the effect of the SST feedback on the atmospheric circulation is derived from the storm track and the associated time series of the MSLP minima, shown in Figures 7 and 16a. The atmosphere-ocean coupling plays a role in modulating both storm track trajectory and intensity. Until 1200 UTC 04 May 2010, the simulated track in EXP3, follows closely the EXP2 simulated track. Then, the colder SST in EXP3 (WRF SST in EXP2 is constant) leads to 

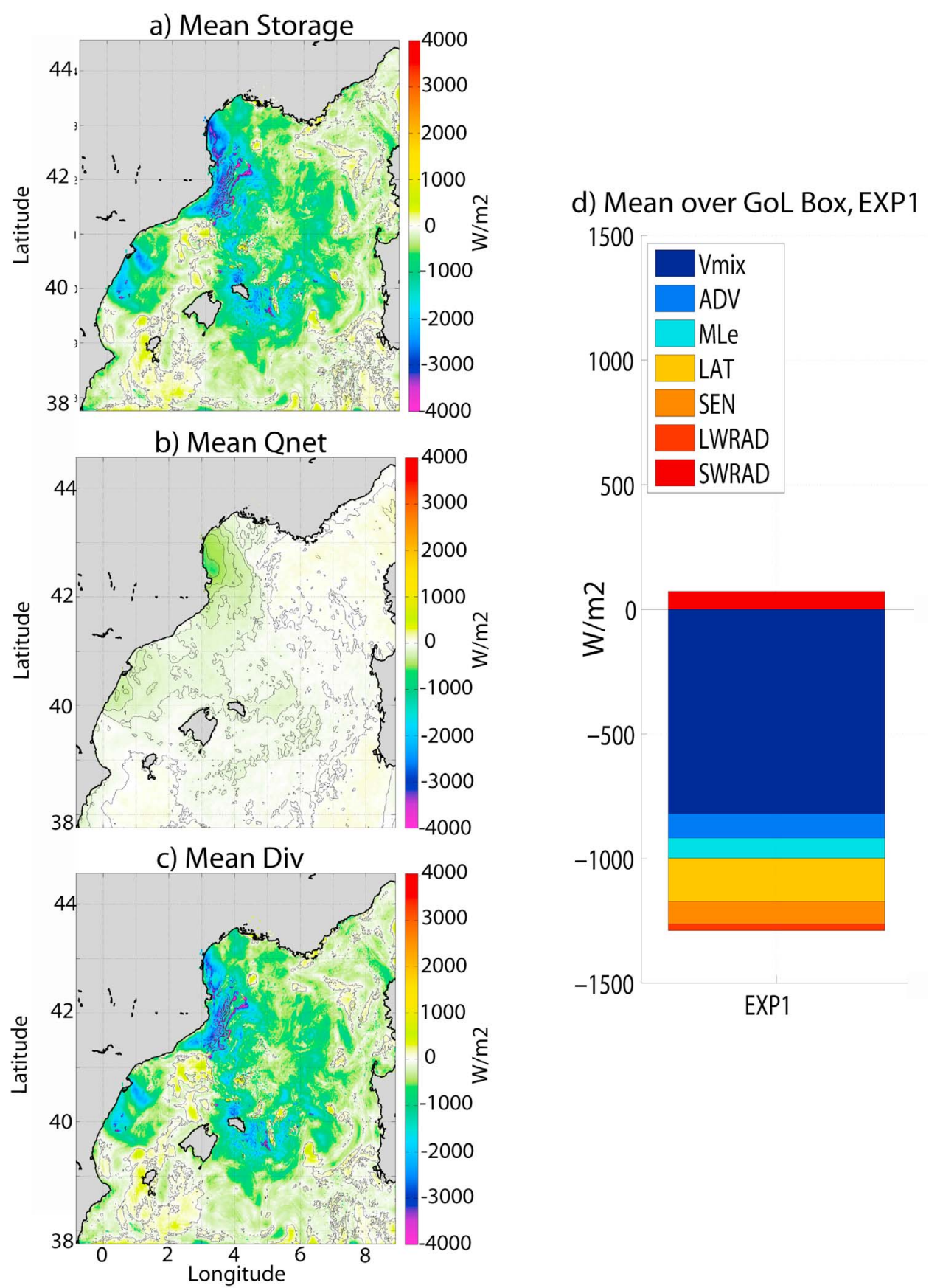

Figure 12. Mean of the mixed layer depth integrated heat budget of the 04 May 2010: (a) Mean storage, (b) mean net air-sea flux (Qnet) and (c) mean divergence (Div). Positive values cause warming. (d) Contributions of each tendency of the heat budget (see Appendix A) over the GoL box (see Figure 5b and Appendix A): Ocean Vertical mixing (Vmix), horizontal and vertical advection (ADV), mixed layer entrainment (MLe), latent heat flux (LAT), sensible heat flux (SEN), longwave radiation (LWRAD) and shortwave radiation (SWRAD) heat. Positive values indicate warming.

storm track displacement differences with respect to EXP2 between $20 \mathrm{~km}$ and $50 \mathrm{~km}$. EXP1 and EXP2 atmospheric simulations do not have a SST update; they are forced by a constant SST that corresponds to the one at 0000 UTC 03 May 2010. Therefore, since the SST that forced WRF in EXP1/EXP2 does not represent the storm induced cooling, the storm simulation by WRF is driven by a too warm SST.
In EXP3, when allowing SST feedback, the SST along the storm track that forced WRF becomes colder (Figure 16b). The associated $\mathrm{T} 2 \mathrm{~m}$ is adjusted, becoming also colder with respect to EXP2 T2m (Figure 16c). Along the storm track, the air-sea temperature gradient $(\Delta \mathrm{T})$, (Figure 16d) at 0600 UTC 04 May 2010 is more intense in EXP3 (colder T2m but colder SST in EXP3 than EXP1/EXP2, Figure 16d). 


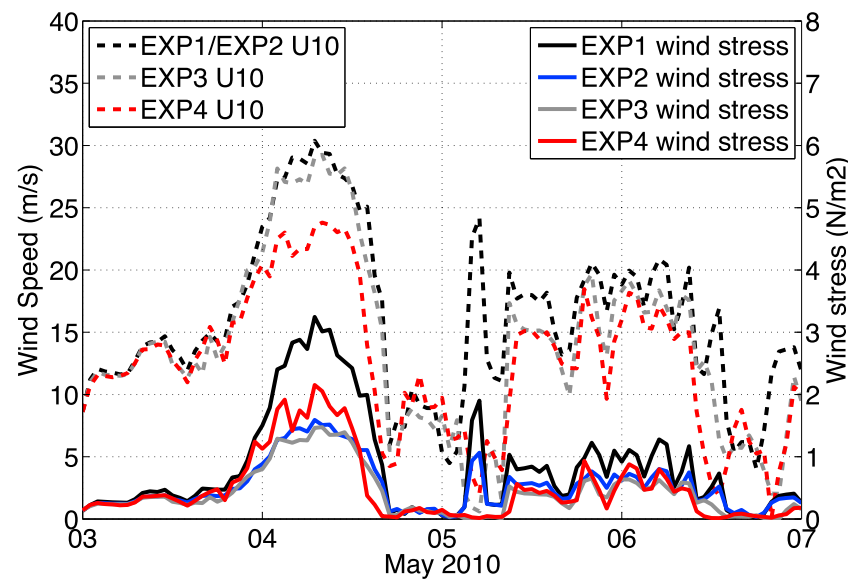

Figure 13. Wind speed (dashed lines) versus wind stress (solid lines) at $\mathrm{CB}$. The black, gray and red dashed lines represent the $10 \mathrm{~m}$ wind speed as simulated at CB by EXP1/ EXP2, EXP3 and EXP4 respectively. The black, blue, gray and red solid lines represent the wind stress at $\mathrm{CB}$ as simulated by EXP1, EXP2, EXP3, and EXP4 respectively.

This induced a slightly deeper storm (Figure 16a) in the initial stage but a faster relaxation to higher values of MSLP in the final stage.

[56] SST feedback to atmosphere leads to two main impacts on the wind field. First, the shift of storm core position described above leads to a similar translation of the maximum wind speed. As a result, wind speed differences at the end of storm (Figure 17a) can locally reach $+/-8 \mathrm{~m} \cdot \mathrm{s}^{-1}$. Second, in EXP3, the advection of relatively warm boundary layer air over colder SST than in EXP1/EXP2 stabilizes the atmospheric marine boundary layer and decouples the surface winds from the winds aloft, decreasing the surface winds. As a result, $10 \mathrm{~m}$ wind speed can locally be reduced by $2 \mathrm{~m} \cdot \mathrm{s}^{-1}$ (not shown). Nevertheless, the Tramontane wind intensification over the GoL (up to $30 \mathrm{~m}^{-\mathrm{s}^{-1}}$ ) is similar between both simulations and is still overestimated in EXP3 with respect to ASCAT and buoys measurments (Figures 4a, 8a, and 9). Finally, at the end of the storm, EXP1/EXP2, due to a too warm constant WRF SST, simulates a persistent sustained Tramontane wind (up to $17 \mathrm{~m} \cdot \mathrm{s}^{-1}$ ). In EXP3, the colder SST, stabilizing the atmospheric marine boundary layer, reduces this persistent Tramontane by $4 \mathrm{~m} . \mathrm{s}^{-1}$.

[57] T2m sensitivity to the air-sea coupling is illustrated on Figure $17 \mathrm{~b}$ by plotting the snapshots of $\mathrm{T} 2 \mathrm{~m}$ differences between EXP3 and EXP1/EXP2. At 1200 UTC 04 May 2010, due to a colder SST in EXP3, T2m differences between EXP3 and EXP1/EXP2 reach up to $1^{\circ} \mathrm{C}$ over the Tramontane wind intensification zone. At 1200 UTC 05 May 2010, again, due to the WRF constant SST, T2m differences increase up to $2^{\circ} \mathrm{C}$ over the $\mathrm{GoL}$ and the $\mathrm{BS}$ (Figure $8 \mathrm{~b}$ ).

[58] The effect of the SST feedback is weakly represented in the MSLP scores (Table 1). There is, however, a $0.5 \mathrm{hPa}$ improvement in the mean bias going from EXP1/EXP2 to EXP3. Looking at the $10 \mathrm{~m}$ wind speed (Table 2), it shows generally as large increase in accuracy from EXP3 as EXP1/ EXP2. In particular, in CB (Figure 8b), although the wind is still overestimated during the storm peak by $5 \mathrm{~m} . \mathrm{s}^{-1}$, the mean bias between observations in reduced more than $2 \mathrm{~m} \cdot \mathrm{s}^{-1}$. Table 3 shows a significant increase of accuracy from EXP1/EXP2 to EXP3. In particular, at CB buoy, during the storm peak, T2m bias with respect to the observations is reduced by $0.8^{\circ} \mathrm{C}$.

\subsubsection{Impact on the Oceanic Response}

[59] EXP3 overcomes the issue raised in section 5.1 (i.e., lack of feedbacks) since atmospheric fields are now coherent with the oceanic fields. As a result, the EXP3 colder SST stabilizes the atmosphere and then weakens momentum flux slightly (by $\sim 5 \%$, Figure 13 ). In particular, over the GoL box, heat loss by ocean vertical mixing and by heat fluxes decreases from $-440 \mathrm{~W} / \mathrm{m}^{2}$ to $-391 \mathrm{~W} / \mathrm{m}^{2}(11 \%)$ and from $430 \mathrm{~W} / \mathrm{m}^{2}$ to $320 \mathrm{~W} / \mathrm{m}^{2}(25 \%)$ respectively (Figures $15 \mathrm{c}$ and $15 \mathrm{~g})$. Along the storm track, the SST feedback decreases slightly $(<5 \%)$ the heat loss by ocean vertical mixing (Figure 15d). Lateral advection and ML entrainment also show a slight sensitivity to the SST feedbacks $(\sim 10-15 \%)$
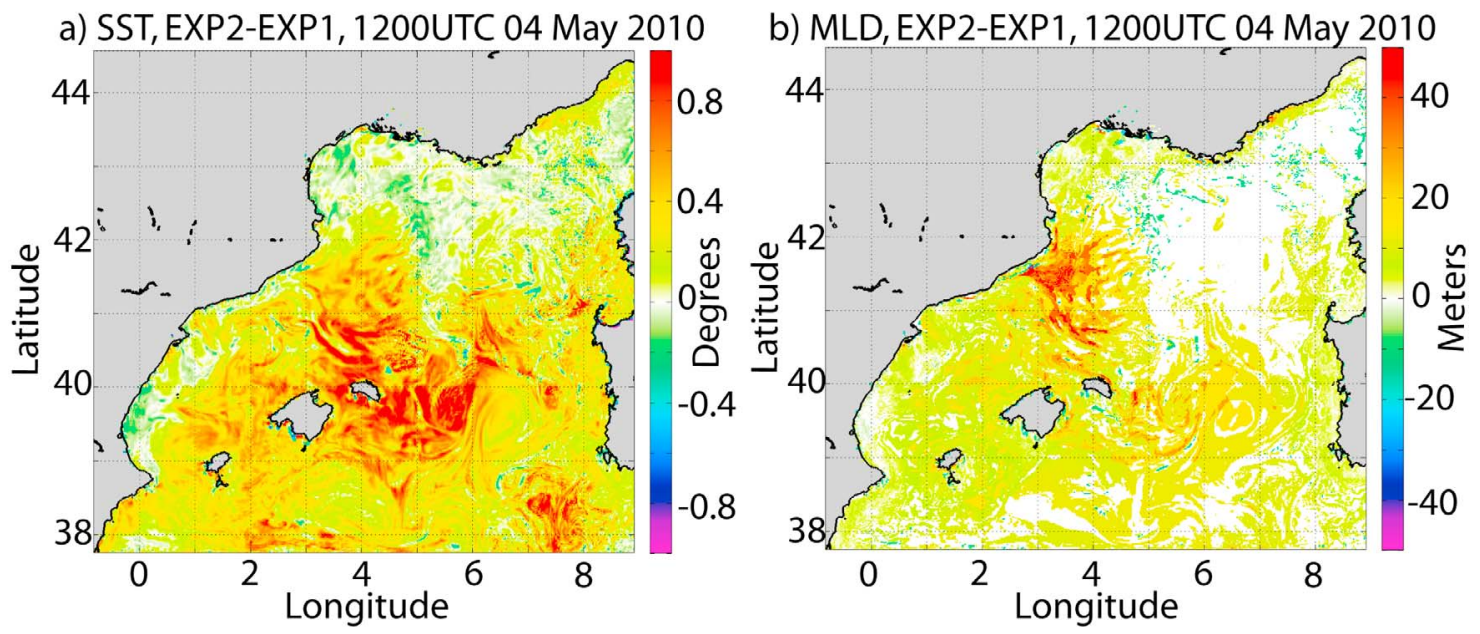

Figure 14. Sea surace temperateure (SST) and mixed layer depth (MLD) sensitivity to the flux parameterization. The color fields represent the differences between EXP2 and EXP1 in terms of (a) SST in degrees C and (b) MLD in meters at 1200 UTC 04 May 2010. 


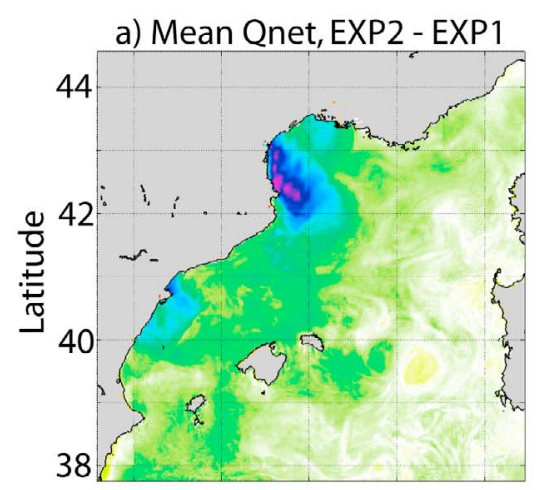

b) Mean DIV, EXP2 - EXP1

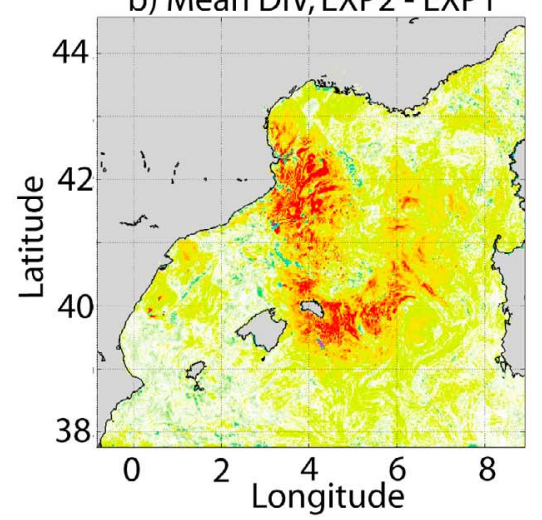

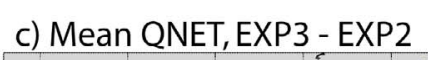

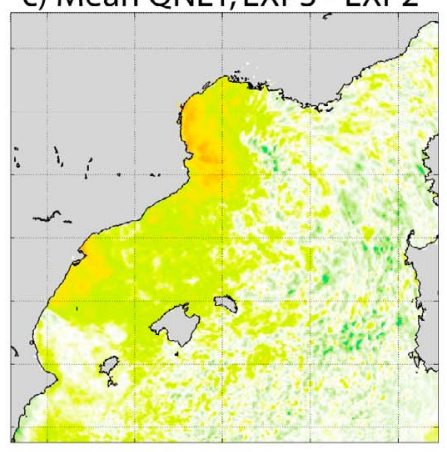

d) Mean DIV, EXP3 - EXP2

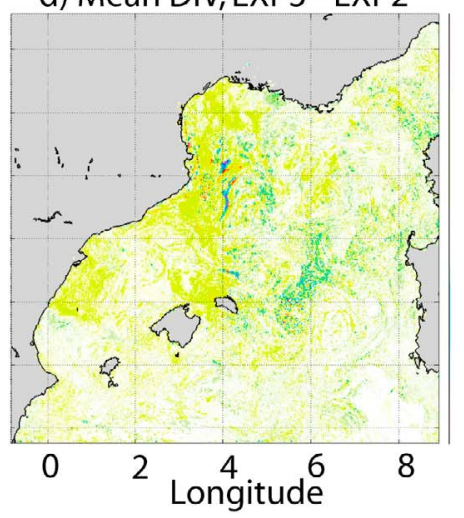

g) Mean over the GoL box
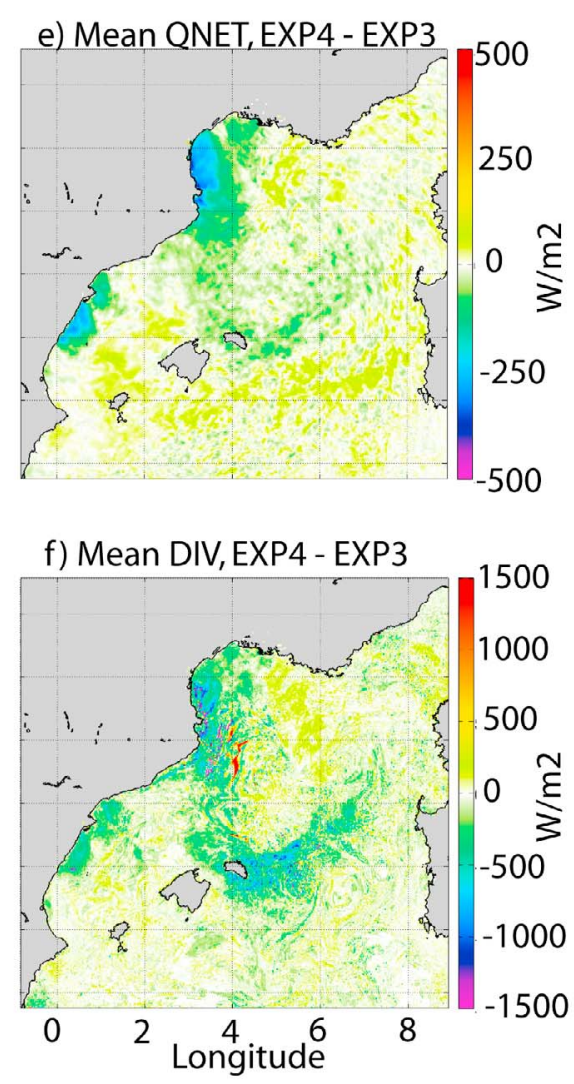

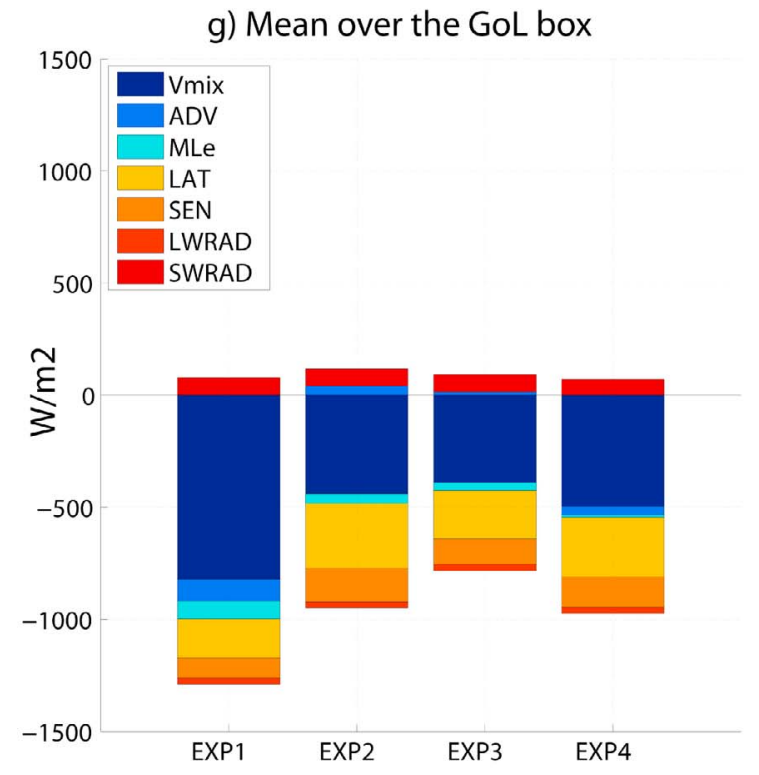

Figure 15. Sensitivity of the mixed layer depth integrated heat budget of the 04 May 2010. Mean net air-sea fluxes (Qnet) and mean divergence (DIV) differences between (a and b) EXP2 and EXP1 (c and d) EXP3 and EXP2 and (e and f) EXP4 and EXP3. For instance, when comparing EXP2 to EXP1, positive values mean EXP1 induces more cooling than EXP2. (g) Contributions of each tendency of the heat budget for each experiment averaged over the GoL box (see Figure 5b and Appendix A): Ocean Vertical mixing (Vmix), horizontal and vertical advection (ADV), Mixed Layer Entrainment (MLe), latent heat flux (LAT), sensible heat flux (SEN), Longwave radiation (LWRAD) and Shortwave Radiation (SWRAD) heat. Positive values indicate warming. 

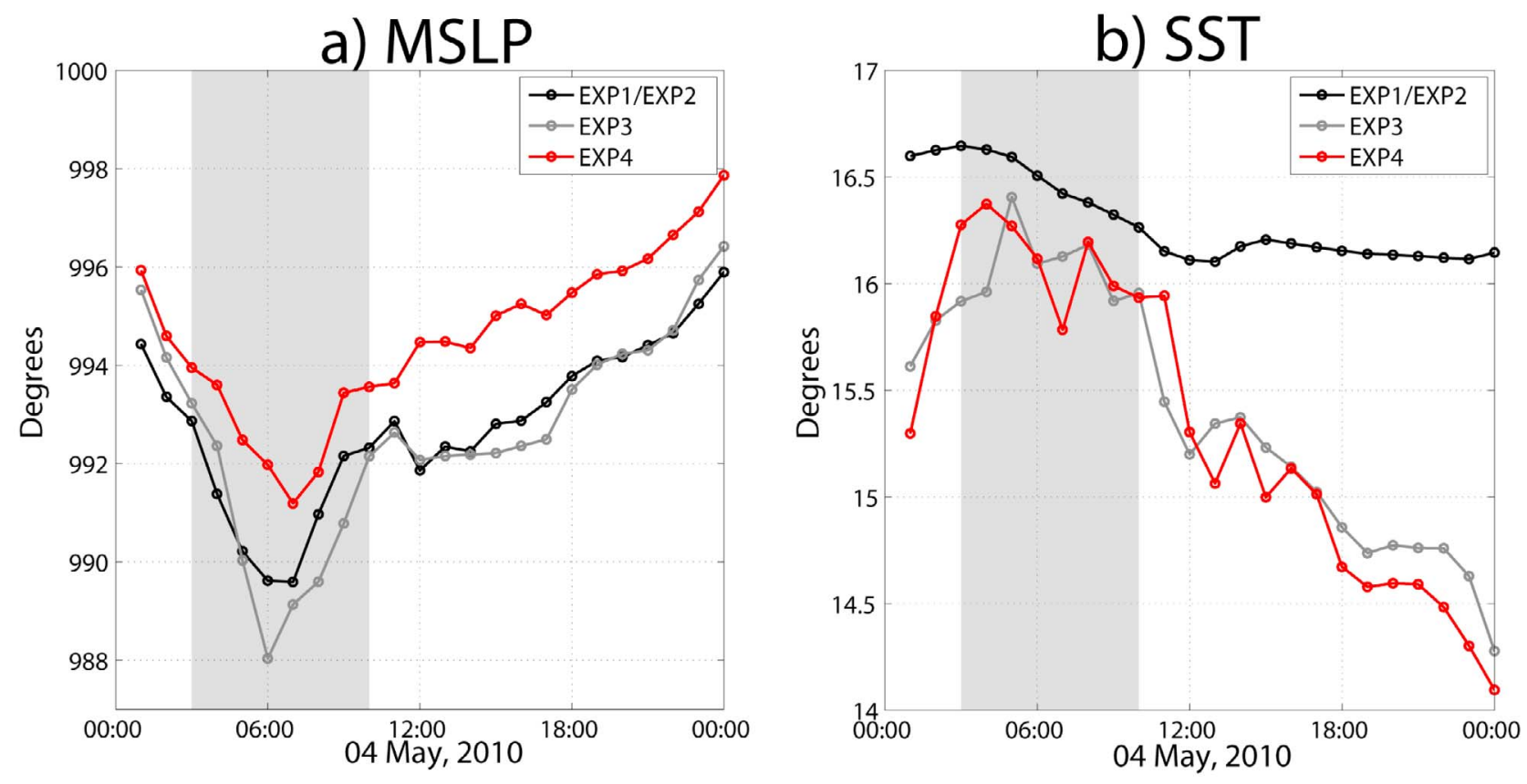

c) $\mathrm{T} 2 \mathrm{~m}$

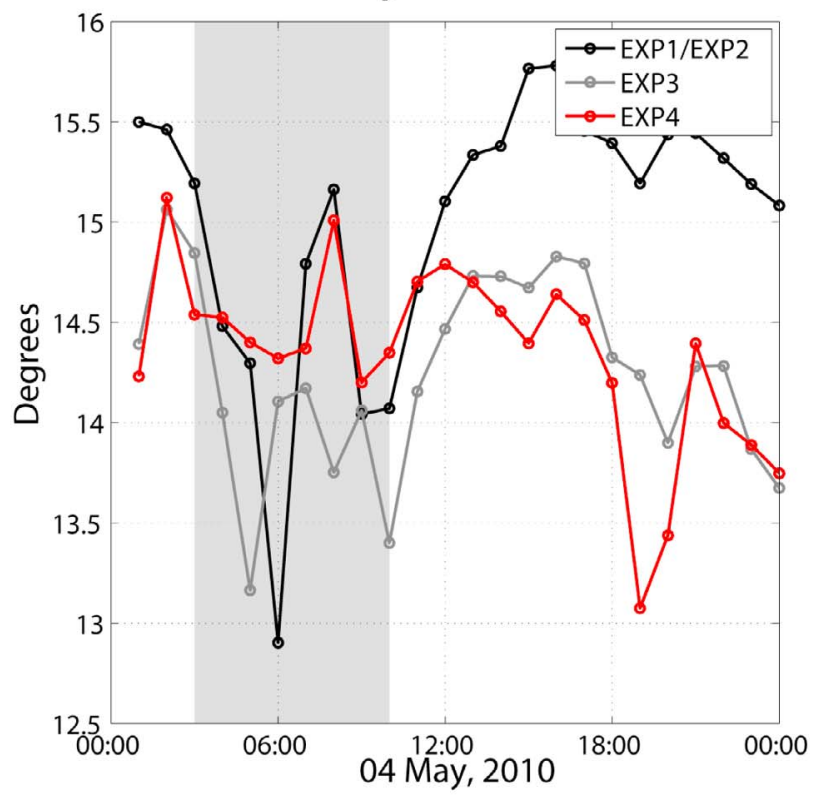

d) T2m-SST

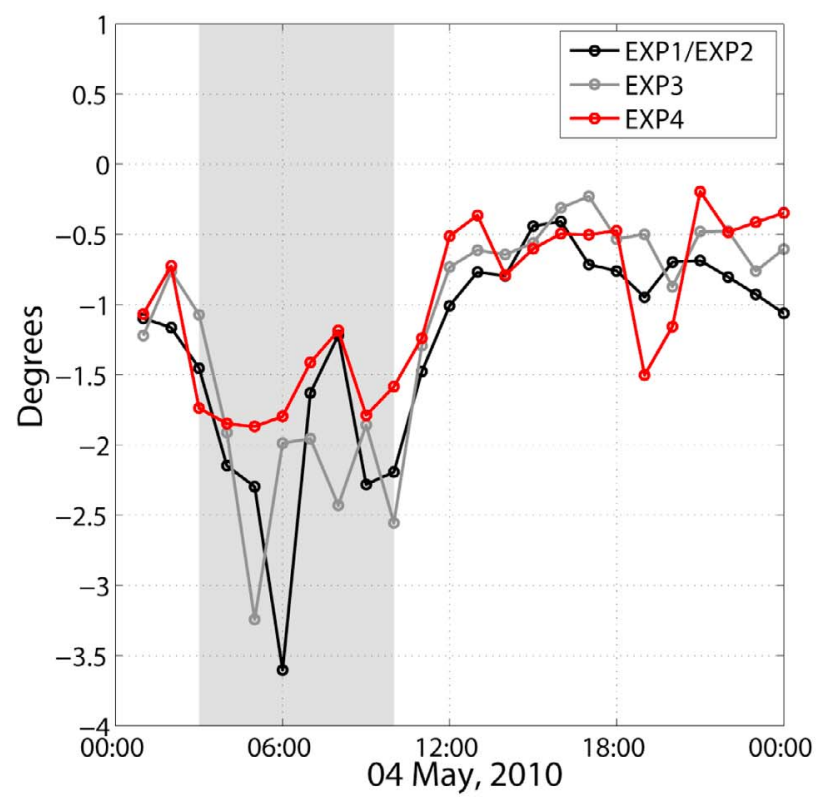

Figure 16. Storm alongtrack parameters. Black, gray and red lines represent respectively EXP1/EXP2, EXP3 and EXP4 and gray filled highlight the storm peak. (a) Mean sea level pressure (MSLP), (b) sea surface temperature (SST) seen by WRF, (c) $2 \mathrm{~m}$ air temperature (T2m) and (d) difference between $\mathrm{T} 2 \mathrm{~m}$ and SST seen by WRF.

whereas longwave and shortwave radiation are not clearly impacted. Note however that these terms do not play a primary role in explaining the cooling of the SST.

[60] As a consequence, at 1200 UTC 04 May 2010 (Figure 18a), the cooling induced by the storm in EXP3 is reduced up to $0.3^{\circ} \mathrm{C}$ over the GoL and $\mathrm{BS}$ with respect to the one simulated by EXP2 oceanic simulation. At this stage, the wavefield is slightly marked by the storm track position change, with differences between EXP3 and EXP2 reaching locally up to $1.5 \mathrm{~m}$. (Figure 18b) as a consequence of the reduced or shifted wind speed. After $60 \mathrm{~h}$ of integration, at 1200 UTC 05 May 2010, SST from EXP3 is still warmer than ROMS EXP2 SST (up to $0.5^{\circ} \mathrm{C}$ ) over the $\mathrm{GoL}$ and the $\mathrm{BS}$ and is similar over the rest of the domain (not shown). Finally, air-sea coupling has a slight impact on the MLD. The local induced weakening of the wind leads at the end of the storm (1200 UTC 05 May 2010, not shown) to a reduced deepening of the ML by $\sim 10 \mathrm{~m}$ overall the domain; 

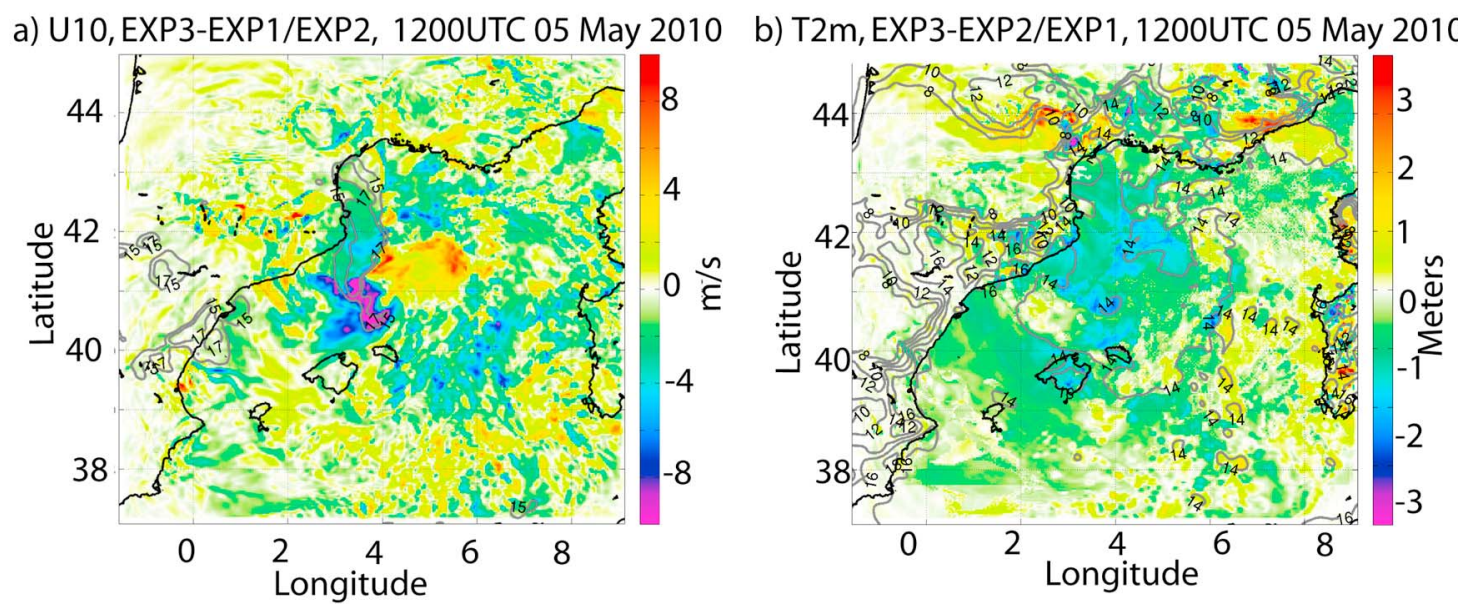

Figure 17. The $10 \mathrm{~m}$ wind speed (U10) and $2 \mathrm{~m}$ air temperature (T2m) sensitivity to the air-sea coupling at 1200 UTC 05 May 2010. (a) U10 differences between EXP3 and EXP2. (b) T2m differences between EXP3 and EXP2.

however, at Cabo Begur, since the wind is similar in EXP3 and EXP2, the deepening of the ML is not significantly impacted.

[61] Reduced errors on the wind field (Table 2) have eventual consequences on the wavefield. Table 5 shows the scores for the Hsig at CB, Mahon and GL buoys. Accordingly, scores are better in EXP3, with substantial reduction of the mean bias, RMSE and scatter index (the ratio of RMSE over the mean of the observations [e.g., Ardhuin et al., 2007]). However, the maximum Hsig and Tp during the storm peak are still overestimated in EXP3 by $2.5 \mathrm{~m}$ and $2 \mathrm{~s}$ respectively (see Figures $10 \mathrm{~b}$ and $10 \mathrm{c}$ ). Impact on the realism of the SST field is more difficult to interpret. At GL buoy, the increased ocean vertical mixing is compensated by the decreased heat fluxes, in which case there is no significant difference (Figure 10a and Table 4). On the other hand, at Dragonera, the overestimated cooling is reduced while the opposite effect is observed at Tarragona buoy where the SST realism is degraded (Table 4).

\subsection{Atmosphere-Wave Coupling: EXP4 Versus EXP3}

[62] In this section, the impact of the wave feedback to the atmosphere on the simulation is assessed comparing EXP4 to EXP3. The main findings show that there are two main competing processes driving the response of models to the wave feedback. On one hand, the sea-state induced roughness changes the estimation of the drag coefficient and increases the momentum flux. This decelerates the $10 \mathrm{~m}$ wind speed and, at the same time, induces more ocean vertical mixing and turbulent heat fluxes and therefore a more intense cooling of SST. A colder SST then stabilizes the atmospheric marine boundary layer and eventually gives a weaker $10 \mathrm{~m}$ wind speed by decoupling the surface winds from the winds aloft. On the other hand, the overall weakening of the wind speed has a negative feedback on the momentum flux estimation. This in fact decreases Hsig and then the roughness and the wind stress. The cooling of SST
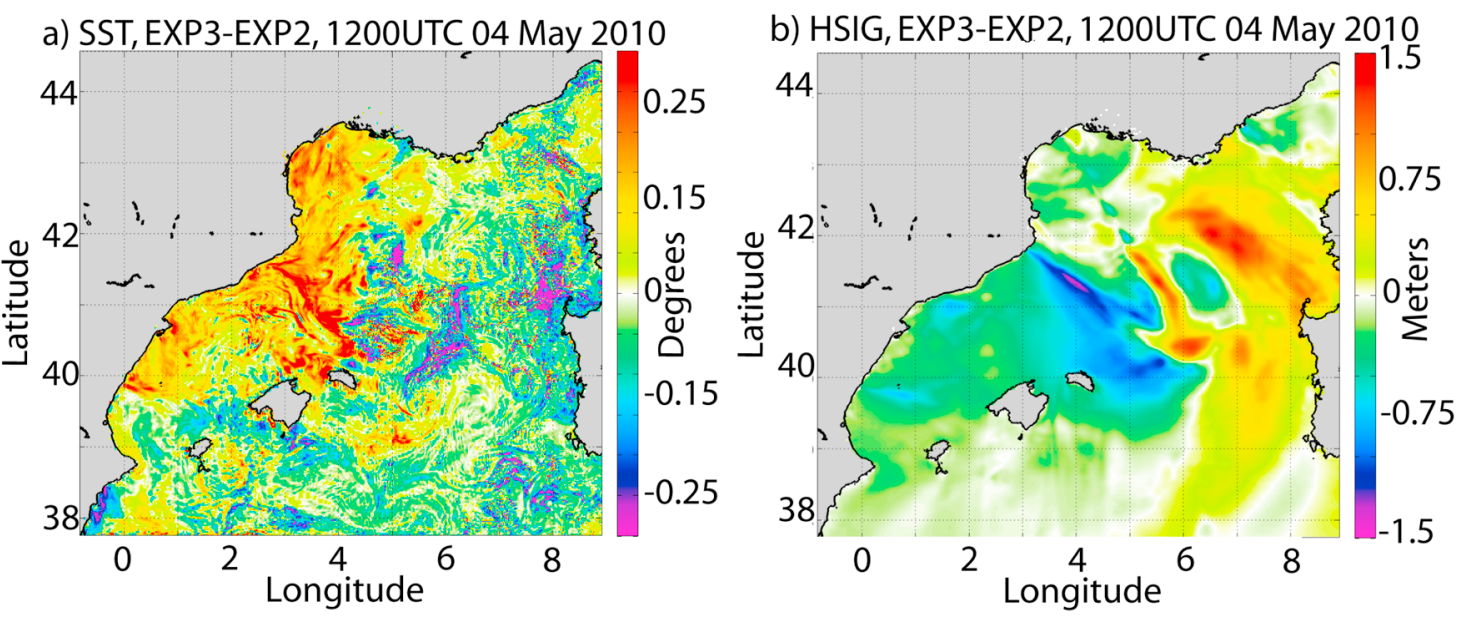

Figure 18. (a) Sea surface temperature (SST) and (b) significant wave height (Hsig) sensitivity to the air-sea coupling at at 1200 UTC 04 May 2010. 
Table 5. Statistics Between Model and Available In Situ Observations of Hsig From 03 May 2010 to 07 May 2010

\begin{tabular}{|c|c|c|c|c|c|c|c|c|c|}
\hline \multirow[b]{2}{*}{ Hsig } & \multicolumn{3}{|c|}{$\begin{array}{c}\text { Cabo Begur } \\
\text { (97 Observations) }\end{array}$} & \multicolumn{3}{|c|}{$\begin{array}{c}\text { Mahon } \\
\text { (97 Observations) }\end{array}$} & \multicolumn{3}{|c|}{$\begin{array}{c}\text { Gulf of Lion } \\
\text { (97 Observations) }\end{array}$} \\
\hline & MB & SI & $\mathrm{R}$ & MB & SI & $\mathrm{R}$ & MB & SI & $\mathrm{R}$ \\
\hline Exp1/Exp2 & 1.52 & 0.77 & 0.92 & 0.81 & 0.58 & 0.85 & 0.65 & 0.39 & 0.90 \\
\hline Exp3 & 1.07 & 0.56 & 0.96 & 0.67 & 0.47 & 0.90 & 0.51 & 0.35 & 0.89 \\
\hline Exp4 & 0.69 & 0.36 & 0.96 & 0.35 & 0.35 & 0.81 & 0.14 & 0.22 & 0.88 \\
\hline
\end{tabular}

${ }^{\mathrm{a}} \mathrm{MB}$ is the Mean Bias, SI the Scatter Index R the correlation.

is then reduced. EXP4 provides the best picture of the studied event.

\subsubsection{Impact on the Oceanic Response}

[63] As illustrated in Figure 13 at Cabo Begur, due to the presence of young sea-states, the momentum flux in EXP4 is amplified during the storm peak from $\sim 1.3 \mathrm{~N} / \mathrm{m}^{2}$ to $\sim 2 \mathrm{~N} / \mathrm{m}^{2}$. Therefore, over the GoL box, wave feedback to atmosphere increases the ocean vertical mixing from $-391 \mathrm{~W} / \mathrm{m}^{2}$ to $-494 \mathrm{~W} / \mathrm{m}^{2}$ ( $25 \%$, Figure $\left.15 \mathrm{~g}\right)$. Along the storm track, ocean vertical mixing is increased by $10 \%$ (Figure 15f). Heat loss through heat fluxes in EXP4 is also increased over the GoL box by $136 \mathrm{~W} / \mathrm{m}^{2}$ and $27 \mathrm{~W} / \mathrm{m}^{2}$ for latent and sensible heat fluxes respectively, and is now similar to heat loss in EXP2 (Figures $15 \mathrm{e}$ and $15 \mathrm{~g}$ ). As a result, at 1200 UTC 04 May 2010, after $36 \mathrm{~h}$ of integration (Figure 19a), over the GoL and BS, EXP4 SST is colder ( $\sim 0.5^{\circ} \mathrm{C}$, up to one degree along the storm track) than EXP3. Additionally, EXP4 presents a deeper ML over the whole domain than EXP3 by $\sim 10 \mathrm{~m}$ at the end of the storm. In particular, the MLD near Cabo Begur reaches up $90 \mathrm{~m}$. (not shown). Surface currents do not present significant changes from EXP3 to EXP4.

\subsubsection{Impact on the Atmosphere and Wavefields}

[64] The wave feedback to the atmopshere increases the ocean-atmosphere interactions. Indeed, the differences of SST and wave roughness have, as expected, a direct impact on the wind field. Figure $19 \mathrm{~b}$ provides comparisons between the $10 \mathrm{~m}$ wind speed as simulated by EXP3 and EXP4 at 1200 UTC 04 May 2010. During the peak of the event, Tramontane wind advects relatively warm boundary layer air over colder SST than in EXP3. It stabilizes the atmospheric marine boundary layer and decouples the surface winds from the winds aloft. The sea induced roughness also produced a low level convergence that may lead the low pressure system to gradually fill, weakening the horizontal pressure gradient and then the surface wind. Finally, the surface winds are reduced up to $4-5 \mathrm{~m} . \mathrm{s}^{-1}$ over the Gol and along the storm track. This has a negative feedback on Hsig.
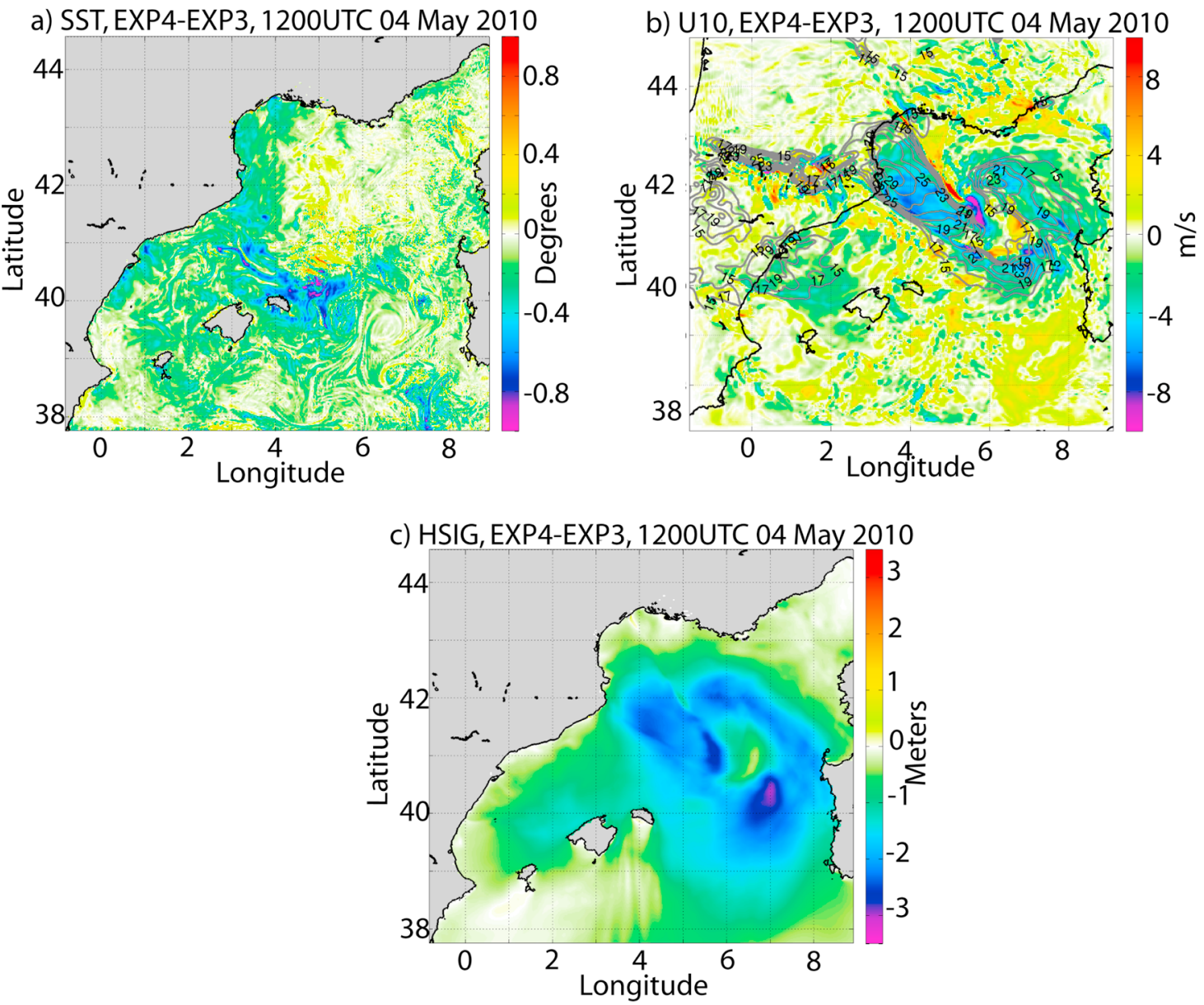

Figure 19. (a) Sea surface temperature (SST), (b) $10 \mathrm{~m}$ wind speed (U10) and (c) significant wave height (Hsig) sensitivity to the air-wave coupling at at 1200 UTC 04 May 2010. 


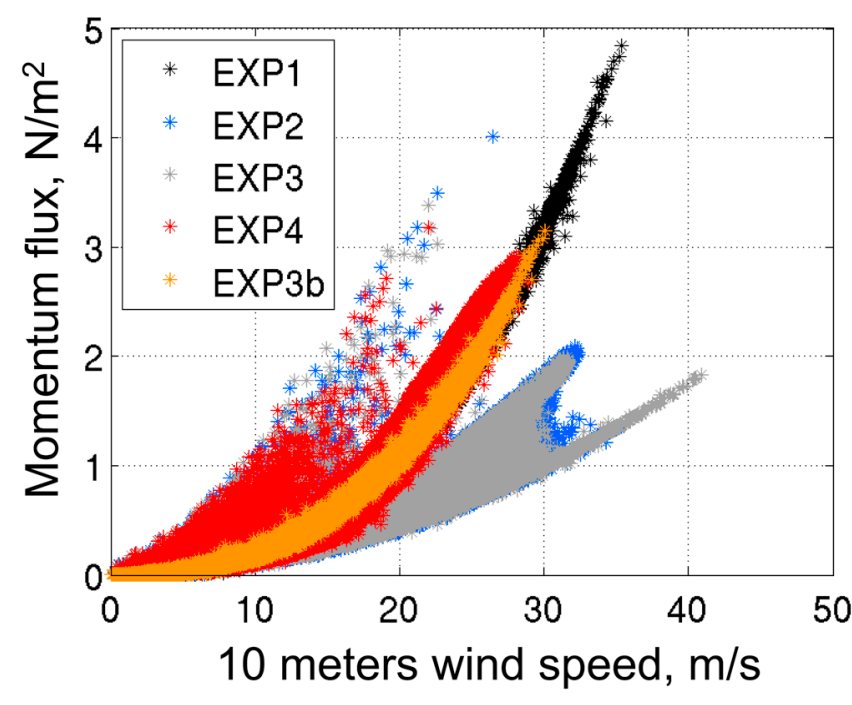

Figure 20. The $10 \mathrm{~m}$ wind speed versus momentum flux overall the simulation period for all the experiments and an additional SST coupled to atmosphere experiment using the BULK_FLUX parameterization (EXP3b, see discussion section at line 1052-1067).

The weakening of the $10 \mathrm{~m}$ wind speed induces a weakening of Hsig from $8 \mathrm{~m}$. to $5 \mathrm{~m}$. (Figures $10 \mathrm{~b}$ and $19 \mathrm{c}$ ) and a shorter $\mathrm{Tp}$ from around $11 \mathrm{~s}$ to $10 \mathrm{~s}$ during the peak of the event (Figure 10c). However, as specified in section 2.1, one can note that the measured wave period at GL is the T1/3 and not the $\mathrm{Tp}$, it might partly explain the differences between model and observations. As a matter of fact, there are two main processes driving the responses of the models to the wave feedback, acting in somewhat opposite way. On one hand, the sea-state induced roughness changes the estimation of the drag coefficient and increases momentum flux. On the other hand, the overall weakening of the wind speed and Hsig has a negative feedback on the momentum flux estimation.

[65] Finally, the additional wave-air feedback has a slight impact on the storm track that is illustrated in Figure $7 \mathrm{a}$ by displaying the simulated storm tracks from the different experiments. At the end of storm, it induces displacement differences around $20 \mathrm{~km}$ as the EXP3 storm track becomes closer to EXP1/EXP2 storm track. Additionally, wave feedback induces a weaker air-sea temperature contrast (Figure 16d). Consequently and consistent with former studies [e.g., Doyle, 2002; Perrie and Zhang, 2001], the storm becomes less deep (Figure 16a): the minimum MSLP is reduced by $3.5 \mathrm{hPa}$ with respect to EXP3. The displacement of the storm track induces again a shift of the wind maximum that is evidenced in Figure 19b by local wind speed differences between EXP3 and EXP4 reaching up to $+-8 \mathrm{~m} \cdot \mathrm{s}^{-1}$ at 1200 UTC 04 May 2010.

\subsubsection{Impact on the Realism of the Simulations}

[66] In good agreement with former studies [e.g., Janssen, 2004], taking into account wave roughness allows WRF parameterization to update the roughness length and then to avoid the constant Charnock parameter parameterization issue highlighted by Garfinkel et al. [2011]. This is indirectly confirmed by comparing results from EXP4 with the available observations. As highlighted in Figure 9, by comparing ASCAT (see Figure 4a) to the simulations, the wave feedback is relevant since it reduced the bias in terms of maximum wind speed from $5 \mathrm{~m} \cdot \mathrm{s}^{-1}$ to less than $1 \mathrm{~m} \cdot \mathrm{s}^{-1}$. Comparison with in situ measurement confirms a clear improvement of the realism of the simulation in EXP4 from EXP3 (see Table 2). In particular, CB buoy wind measurement confirms the reduced bias in terms of wind speed from 4 to $5 \mathrm{~m} \cdot \mathrm{s}^{-1}$ to less than $1 \mathrm{~m} \cdot \mathrm{s}^{-1}$ (Figure $8 \mathrm{~b}$ ). The representation of the MSLP (Table 1 and Figure 8a) is also improved by reducing the bias between observations and model, as well as for T2m (Table 3 and Figure 8c). The improvement in the realism of the atmospheric forcing is transferred to the simulated wavefield, with increase of model skills. The mean bias with respect to the observations is reduced by $0.5 \mathrm{~m}$ and scatter index is half with respect to EXP1. The increase of skills is also evidenced in Figure 10c. The Hsig and Tp biases during the peak of the event are also reduced from $3 \mathrm{~m}$. to less than $0.5 \mathrm{~m}$. and from $11 \mathrm{~s}$ to $10 \mathrm{~s}$ respectively, improving the realism of the simulation. Although the feedback has a positive impact on the atmospheric simulation and on the wave simulation, the improvement of the oceanic response is more difficult to assess directly as the available buoys are not located where these feedbacks have a major impact. In any case, as in previous studies [e.g., Lionello et al., 2003; Janssen et al., 2004], these results confirm that wave feedback to the atmosphere is relevant.

\section{Discussion}

[67] Discrepancies between observations and simulations can be due to several factors that are analyzed in this section. The oceanic initial conditions are biased compared to observations due to inaccuracies in boundary conditions, atmospheric forcing, and the eventual lack of coupling during the spin-up phase. Any improvement of these conditions could improve oceanic response realism and, by SST feedback, the atmospheric simulation realism. Uncertainties due to the low temporal and spatial resolution of the atmospheric initial and boundary conditions can also lead to some biases both in location and timing of the low pressure. Former simulations (not shown) forced and initialized by NCEP2 $\left(2.5^{\circ} \times 2.5^{\circ}\right)$ [Kalnay et al., 1996] simulated also a cyclogenesis; however, the simulated storm track did not loop over the GoL. Improving the spatial/temporal resolutions of the atmospheric initial and boundary conditions could reduce differences between model and observations.

[68] In this study, by incorporating the wave roughness into the momentum flux parameterization, results improve. As in Garfinkel et al. [2011] and Janssen et al. [2002, 2004], the parameterization based on a constant Charnock coefficient (like, e.g., ATM_FLUX) likely underestimates the drag coefficient and then momemtum stress in case of intense wind speed. To illustrate this, Figure 20 displays the wind speed - momentum flux diagram over the simulation period for all the experiments. BULK_FLUX (EXP1) and ATM FLUX without wave coupling (EXP2 and EXP3) show large differences in terms of momentum flux. In particular, for intense wind speed (e.g., more than $20 \mathrm{~m} . \mathrm{s}^{-1}$ ), momentum flux estimated using BULK_FLUX can be more than twice 
the one estimated using ATM FLUX in EXP2 or EXP3. It should be noted that the validity of Fairall et al. [2003] is also questionable at wind speed well above $20 \mathrm{~m} \cdot \mathrm{s}^{-1}$. In EXP4, with the inclusion of the wave feedback to the atmosphere, the momentum flux is similar to the values obtained using the BULK_FLUX parameterization [Fairall et al., 2003]. Since the storm induced cooling is driven mainly by ocean vertical mixing and turbulent heat fluxes, a relatively lower friction velocity in EXP3 induces a weak SST cooling that in turn does not have a significant impact on the maximum wind speed during the storm. In EXP4, $10 \mathrm{~m}$ wind speed is weakened by the combined effect of sea roughness that induces a low level convergence and an enhanced momentum flux that increases SST cooling stabilizing the atmospheric marine boundary layer. These feedbacks reduce the biases with respect to the observations (refer to Figure 8b). This result confirms the Janssen [2004] study and also the Fairall et al. [2003] study, which show that for wind speed greater than about $5 \mathrm{~m} . \mathrm{s}^{-1}$, surface waves are a dominant factor in the surface roughness of the ocean. Additionally, the reduction in surface wind speeds and consequently in wave height is consistent with previous atmosphere-wave numerical experiments [e.g., Weber et al., 1993; Doyle, 1995; Janssen and Viterbo, 1996; Desjardins et al., 2000; Warner et al., 2010; Olabarrieta et al., 2012].

[69] An additional experiment (EXP3b), which uses the same coupling way as EXP3, has been carried out using the BULK_FLUX parameterization. Although this experiment is not physically correct (it does not allow for conservation of fluxes between ocean and atmosphere models since two different parameterizations are used to compute the exchange at the interface), results from BULK_FLUX were similar to the EXP4 ATM_FLUX results, i.e., the MYJSFC scheme, once including the effect of the sea-state, gives results comparable to the Fairall parameterization implemented in ROMS. As illustrated in Figure 20, since under high wind speed conditions the momentum flux and the wind speed from this additional experiment are quite similar to the ones from EXP4, the oceanic and surface wave responses are very close to the ones simulated by EXP4 (not shown).

[70] There are several methods to couple atmospheric model to wave model. In this study, the wave model (SWAN) provides to the atmospheric model (WRF) the significant wave height, wave peak period, and wavelength. Then, the Drennan et al. [2005] parameterization is used by WRF to compute the surface roughness based on wave age. Another way of coupling the atmospheric model to the wave model may be implemented following the method described by Janssen [2004]. This method is used at the European Centre for Medium-Range Weather Forecasts (ECMWF) forecast and has been demonstrated relevant for both the wave and the atmospheric models [Janssen et al., 2002, 2004]. Comparing different approaches available in the literature [e.g., Olabarrieta et al., 2012] is beyond the scope of this investigation but certainly calls for further research efforts.

[71] Using a fully coupled system allows overcoming some inconsistencies in the computation of turbulent fluxes with respect to uncoupled models. Even though WRF parameterizations used in the coupled experiment are not specifically dedicated for marine conditions. Using the Fairall et al. [2003] formulation within WRF over the sea cells and the MYJSFC scheme over land cells might improve the performance of the system despite some expected instabilities at the land-sea boundary. Nevetheless, at high wind speed, such formulation may overestimate wind stress. A similar approach was tested recently by May et al. [2011] and needs further research.

[72] Other sources of model errors are possible. In particular, it may be argued that since the turbulent heat fluxes parameterizations have a strong dependence on aerodynamical surface roughness [e.g., Bao et al., 2000], not all atmospheric model parameterisation would benefit equally from the wave-atmosphere coupling. In addition, as suggested by S. E. Belcher et al. (A global perspective on mixing in the ocean surface boundary layer, submitted to Geophysical Research Letters, 2011), current parameterizations of the oceanic turbulent mixing are likely missing key surfacewave processes that force Langmuir turbulence, which deepens the oceanic mixed layer more rapidly than wind-forcing. This may lead to systematic and substantial error in the simulation of the oceanic mixed layer, impacting the heat exchange between ocean and atmosphere.

[73] A further analysis would be necessary to incorporate additional effects of wave-current interaction using the Vortex Force approach to fully account for the effect of surface waves breaking and providing a source of momentum to the ocean. This increase in flux would modify the ocean mixed layer deepening and the currents [e.g., Qiao et al., 2006; Carniel et al., 2009; Babanin, 2011; Olabarrieta et al., 2012] that would be returned to the wave model in a vertically integrated approach based on Kirby and Chen [1989]. Such impact may change the storm induced SST cooling and then the atmospheric and wave simulations by SST feedback to the atmosphere. This additional investigation is something to be considered and addressed in additional scenarios to be performed in the future. In addition, when coupling the three models, the momentum flux estimated by WRF including the effect of the sea-state is transferred as drag over the ocean model without considering here the momentum flux portion lost to surface waves (as, for example, in Janssen et al. [1989], Saetra et al. [2007] and Fan et al. [2009]) nor the one locally gained through breaking waves. This may result in a biased estimation of ocean vertical mixing and then SST cooling in EXP4.

[74] Results suggest that the studied storm is not a tropical cyclone like Mediterranean storms in which the wind induced surface heat exchange mechanism [e.g., Emanuel, 1988; Jansá, 1987; Pytharoulis et al., 2000] assumes a primary role. In the studied case, like in some meteorological bombs studied by Katsafados et al. [2011], surface fluxes does not seem to play a primary role in the storm location and intensity, which seem to be partially driven by air-sea temperature contrast. Sanders and Gyakum [1980] suggest a criterion, called the Bergeron number, which is defined as the normalized central pressure deepening rate (NDRc)

$$
\mathrm{NDR}_{C}=\frac{\Delta P}{24 \mathrm{hPa}} \frac{\sin (60)}{\sin \phi},
$$

where $P$ is the central pressure change (in $\mathrm{hPa}$ ) of a system over $24 \mathrm{~h}$ that occurs at latitude $\phi$. When the Bergeron number exceeds unity, the system is deemed to be an 
atmospheric bomb in the sense of Sanders and Gyakum [1980]. Therefore, the studied event is not in the strict sense an atmospheric bomb but is close to one, since it is characterized by a Bergeron number of 0.9. Zhang and Perrie [2001] showed that the enhanced roughness due to waves increases the heat loss by turbulent heat fluxes, which in turn fuels the storm and then induces a deeper storm. Our results show instead that EXP4 simulates the less deep storm. The interpretation of this result is that there are two opposite feedback mechanisms in the coupling process between the atmosphere and ocean surface. The more intense heat loss by turbulent heat fluxes fuels the storm, whereas the sea roughness and the SST cooling (driven by the combined effect of turbulent heat fluxes and ocean vertical mixing), by stabilizing the atmospheric marine bounday layer and reducing the air-sea temperature contrast, reduce the storm intensity. In our case study, the second coupling mechanism dominates the first one and then leads to a slightly less deep storm.

[75] Although the fully coupled simulation provides better statistical scores compared to the other simulations, the comparisons were mostly focused on meteo-oceanographic buoys, i.e., at the interface between atmosphere and ocean. Further effort should be devoted to testing the performance of the system in the full atmospheric and ocean boundary layers. Within the framework of the IMEDEA/SOCIB observational program, glider missions are carried out across the Balearic Sea and the Spanish Peninsula [Ruiz et al., 2009, 2012]. High-resolution hydrographic data gathered with such technologies could help us to improve both evaluation and assessment of the coupling sensitivity on shortterm and long-term studies. This is the topic of current research. Finally, this study is also aimed at serving as a benchmark for wave-air-sea coupled simulations, despite the short period studied. Indeed, results can be useful to parameterize the air-sea interactions in climatic simulation and also the air-wave coupling as demonstrated by Hanley et al. [2010].

\section{Conclusion}

[76] In this study, we carried out uncoupled and coupled simulations over the Western Mediterranean Sea to assess the atmosphere-ocean-wave feedback during a severe storm. Despite some biases in terms of intensity and location, this event is relatively well reproduced by the different simulations showing a cyclogenesis starting on 03 May 2010 close to the Balearic Islands and then turning on to the Gulf of Lion. This event induced an intensification of both Mistral and Tramontane wind up to $25 \mathrm{~m} . \mathrm{s}^{-1}$ generating rough seastate with significant wave height up to $5 \mathrm{~m}$. As observed by in situ measurements, the simulated oceanic response to the storm is a significant sea surface cooling (up to $2^{\circ}$ ) over the Gulf of Lion, mostly confined to the Tramontane zone intensification and along the storm track.

[77] Using a surface heat budget analysis, we have found that ocean vertical mixing was a major contributor to the cooling tendency along the storm track and the Gulf of Lion where turbulent heat fluxes also played an important role. In good agreement with other studies [e.g., Garfinkel et al.,
2011], sensitivity experiments to fluxes parameterization showed that the WRF parameterization based on a constant Charnock coefficient leads to a lower momentum flux that in turn induced a weak SST cooling by combined effect of ocean vertical mixing and turbulent heat fluxes. When adding SST feedback to the atmosphere and using this parameterization, the atmospheric marine bounday layer is stabilized and winds are slightly reduced. The inclusion of the wave feedback reinforced the SST feedback to the atmosphere. Considering the effect of the wave age on the roughness length, more intense momentum flux, ocean vertical mixing and turbulent heat fluxes are found. In turn, the induced colder SST stabilized more efficiently the atmospheric marine boundary layer and then, combined with the sea induced roughness that may weaken the horizontal pressure gradient, reduced the biases of $10 \mathrm{~m}$ wind speed and significant wave height between model and observations.

[78] Comparison with available atmospheric and oceanic observations showed that, as in former studies [e.g., Pullen et al., 2007; Lionello et al., 2003], the use of the fully coupled system provides the most skillful simulation, illustrating the benefit of using a fully coupled ocean-atmospherewave model system for the assessment of the storm event. Additionally, although the direct evaluation of momentum flux values is not possible here due to the lack of corresponding observations, this study confirms that the atmosphere-wave coupled models improve the realism of the simulations. While some limitations of this application have been addressed, the realism of the fully coupled simulations is encouraging and provides a road map for further hypothesis testing.

\section{Appendix A}

\section{A1. Heat Budget}

[79] For diagnosing the oceanic processes that drive the differences between the experiments, the following temperature heat budget is computed offline:

$$
\begin{aligned}
\partial_{t}\langle T\rangle= & \frac{Q}{\rho_{0} C_{p} h}-\left\langle U \partial_{x} T+V \partial_{y} T+W \partial_{z} T\right\rangle-\frac{1}{h} \frac{\partial h}{\partial t}\left(S S T-T_{z=h}\right) \\
& +\frac{\partial}{\partial z} k v \frac{\partial T}{\partial z}
\end{aligned}
$$

where $\mathrm{T}$ represents the ocean temperature and SST the sea surface temperature, $(U, V, W)$ is the $3-\mathrm{D}$ velocity field estimated from the simulation, $h$ is the mixed layer depth estimated using a criterion of $0.2^{\circ}$ [de Boyer Montégut et al., 2004] and $Q$ is the net heat flux (sum of latent, sensible, longwave radiation and shortwave radiation heat fluxes). The variables $\rho_{0}$ and $C_{p}$ are the mean density and heat capacity of the ocean water $\left(\rho_{0}=103 \mathrm{~kg} \mathrm{~m}^{-3}\right.$ and $C_{p}=$ $4185.5 \mathrm{Joule} /(\mathrm{kgK}), k v$ is the vertical diffusion coefficient estimated by ROMS. 〈.〉 represents the integral value over the MLD).

[80] Focus is on the Gol, the purple rectangle displayed on Figure $5 \mathrm{~b}$, which indicates the box where heat budget is averaged $\left(2^{\circ} \mathrm{E}-5^{\circ} \mathrm{E}-41.5^{\circ} \mathrm{N}-44^{\circ} \mathrm{N}\right)$. 
Table A1. List of Acronyms

\begin{tabular}{ll}
\hline Acronym & \\
\hline AEMET & Agencia Estatal de METeorología \\
ASCAT & Advanced SCATterometer \\
BS & Balearic Sea \\
CB & Cabo Begur \\
COAMPS & Coupled Ocean AtmosphereMesoscale Prediction System \\
COAWST & Coupled Ocean Atmosphere Wave Sediment Transport \\
ECMWF & European Centre for Medium-Range Weather Forecasts \\
FNL & Final NCEP anaLysis \\
GL & Gulf of Lion buoy \\
GoL & Gulf Of Lion \\
GOS & Gruppo di Oceanografia da Satellite \\
Hirlam & HIgh Resolution Limited Area Model \\
Hsig & Significant wave height \\
MCT & Model Coupling Toolkit \\
ML & Mixed Layer \\
MLD & Mixed Layer Depth \\
MFS & Mediterranean Forecasting System \\
MSLP & Mean Sea Level Pressure \\
MYJSFC & Mellor Yamada Janjíc SurFaCe \\
NCEP & National Centers for Environmental Prediction \\
RMSE & Root Mean Square Error \\
ROMS & Regional Ocean Modeling System \\
SCRIP & Spherical Coordinate Remapping Interpolation Package \\
SST & Sea Surface Temperature \\
SWAN & Simulating WAves Nearshore model \\
T2m & 2 m air temperature \\
Tp & Wave peak period \\
WAM & WAve prediction Model \\
WRF & Weather Research and Forecasting model \\
&
\end{tabular}

\section{A2. Acronyms}

[81] The acronyms detailed in Table A1 are used throughout this study.

[82] Acknowledgments. This work has been partially supported by MyOcean2 EU funded project 283367 whose support is gratefully acknowledged. The use of the data from Puertos del Estado buoys network is also acknowledged. The FNL data (http://dss.ucar.edu/ds083) are from the Research Data Archive (RDA) maintained by the Computational and Information Systems Laboratory (CISL) at the National Center for Atmospheric Research (NCAR). NCAR is sponsored by the National Science Foundation (NSF). Météo France is thanked for the GoL data and the authors are also grateful to K.I Hodges (ESSC) for his useful help with the TRACK software (http://www.nerc-essc.ac.uk/ kih/TRACK/Track.html). Jean-Michel Lellouche, Laurent Copolla and Julie Pullen are deeply acknowledged for fruitful discussions about this work. Augustí Jansá and AEMET are thanked for providing the clouds data. Maitane Olbarrieta, Manel Grifoll and two anonymous reviewers are thanked for their constructive comments and suggestions, which helped to improve the manuscript. We also thank IMEDEA for hosting part of the SOCIB modelling facility.

\section{References}

Alpert, P., and B. Ziv (1989), The Sharav Cyclone, observations and some theoretical considerations, J. Geophys. Res., 94, 18,495-18,514, doi:10.1029/JD094iD15p18495.

Alvarez-Fanjul, E., M. Alfonso, M. I. Ruiz, J. D. López, and I. Rodríguez (2003), Real time monitoring of Spanish coastal waters: The deep water network 2002, in Building the European Capacity in Operational Oceanography: Proceedings of the 3rd International Conference on EuroGOOS, Elsevier Oceanogr. Ser., vol. 69, edited by H. Dahlin et al., pp. 98-402, Elsevier, Amsertdam.

Ardhuin, F., L. Bertotti, J.-R. Bidlot, L. Cavaleri, V. Filipetto, J.-M. Lefevre, and P. Wittmann (2007), Comparison of wind and wave measurements and models in the Western Mediterranean Sea, Ocean Eng., $34(3-4), 526-541$.

Babanin, A. V. (2011), Breaking and Dissipation of Ocean Surface Waves, 480 pp., Cambridge Univ. Press, Cambridge, U. K.

Bao, J.-W., J. M. Wilczak, J.-K. Choi, and L. H. Kantha (2000), Numerical simulations of Air-Sea Interaction under High Wind Conditions using a coupled model: A study of Hurricane Development, Mon. Wea. Rev., 128, 2190-2210, doi:10.1175/1520-0493(2000)128<2190:NSOASI $>2.0$. $\mathrm{CO} ; 2$.

Bartalis, Z., W. Wagner, V. Naeimi, S. Hasenauer, K. Scipal, H. Bonekamp, J. Figa, and C. Anderson (2007), Initial soil moisture retrievals from the METOP-A advanced Scatterometer (ASCAT), Geophys. Res. Lett., 34, L20401, doi:10.1029/2007GL031088.

Bentamy, A., D. Croize-Fillon, and C. Perigaud (2008), Characterization of ASCAT measurements based on buoy and QuikSCAT wind vector observations, Ocean Sci., 4, 265-274, doi:10.5194/os-4-265-2008.

Béthoux, J.-P. (1980), Mean water fluxes across sections in the Mediterranean Sea, evaluated on the basis of water and salt budget and of observed salinities, Oceanol. Acta, 3, 79-88.

Booij, N., R. C. Ris, and L. H. Holthuijsen (1999), A third-generation wave model for coastal regions. 1. Model description and validation, J. Geophys. Res., 104, 7649-7666, doi:10.1029/98JC02622.

Burgers, G. J. H., P. A. E. M. Janssen, and D. L. T. Anderson (1995), Impact of sea-state dependent fluxes on the tropical ocean circulation, Proc. Int. Sci. Conf. Trop. Ocean's Global Atmos., 717, 295-297.

Buzzi, A., and A. Speranza (1986), A theory of deep cyclogenesis in the lee of the Alps, Part II: Effects of finite topographic slope and height, J. Atmos. Sci., 43, 2826-2837.

Campins, J., A. Jansá, B. Benech, E. Koffi, and P. Bessemoulin (1995), PYREX observation and model diagnosis of the Tramontane wind, Meteorol. Atmos. Phys., 56, 209-228.

Campins, J., A. Genoves, A. Jansá, J. A. Guijarro, and C. Ramis (2000), A catalogue and a classification of surface cyclones for the western Mediterranean, Int. J. Climatol., 20, 969-984, doi:10.1002/1097-0088 (200007)20:9<969::AID-JOC519>3.0.CO;2-4

Carniel, S., J. C. Warner, J. Chiggiato, and M. Sclavo (2009), Investigating the impact of surface wave breaking on modeling the trajectories of drifters in the northern Adriatic Sea during a wind-storm event, Ocean Modell., 30, 225-239, doi:10.1016/j.ocemod.2009.07.001.

Charnock, H. (1955), Wind stress over a water surface, Q. J. R. Meteorol. Soc., 81, 639-640, doi:10.1002/qi.49708135027.

de Boyer Montégut, C., G. Madec, A. S. Fischer, A. Lazar, and D. Iudicone (2004), Mixed layer depth over the global ocean: An examination of profile data and a profile-based climatology, J. Geophys. Res., 109, C12003, doi:10.1029/2004JC002378.

Desjardins, S., J. Mailhot, and R. Lalbeharry (2000), Examination of the impact of a couple atmospheric and ocean wave system, part I. Atmospheric aspects, J. Phys. Oceanogr., 30, 385-401, doi:10.1175/15200485(2000)030<0385:EOTIOA $>2.0 . \mathrm{CO} ; 2$

Donelan, M. A. (1990), Air-sea interaction, in The Sea, vol. 9, Ocean Engineering Science, edited by B. LeMehaute and D. M. Hanes, pp. 239-292, Wiley Intersci., New York.

Doyle, J. D. (1995), Coupled ocean wave/atmosphere mesoscale model simulations of cyclogenesis, Tellus Ser. A, 47, 766-788.

Doyle, J. D. (2002), Coupled atmosphere-ocean wave simulations under high wind conditions, Mon. Weather Rev., 130, 3087-3099, doi:10.1175/ 1520-0493(2002)130<3087:CAOWSU >2.0.CO;2.

Drennan, W. M., H. C. Graber, D. Hauser, and C. Quentin (2003), On the wave age dependence of wind stress over pure wind seas, J. Geophys. Res., 108(C3), 8062, doi:10.1029/2000JC000715.

Drennan, W. M., P. K. Taylor, and M. A. Yelland (2005), Parameterizing the sea surface roughness, J. Phys. Oceanogr., 35, 835-848, doi:10.1175/ JPO2704.1.

Edson, J. B. (2008), Review of air-sea transfer processes, paper presented at ECMWF Workshop on Ocean-Atmosphere Interactions, Eur. Cent. For Medium-Range Weather Forecasts, Reading, U. K., 10-12 Nov.

Emanuel, K. A. (1988), Toward a general theory of hurricanes, Am. Sci., 76 , 371-379.

Estournel, C., X. Durrieu de Madron, P. Marsaleix, F. Auclair, C. Julliand, and R. Vehil (2003), Observation and modeling of the winter coastal oceanic circulation in the Gulf of Lion under wind conditions influenced by the continental orography (FETCH experiment), J. Geophys. Res., 108(C3), 8059, doi:10.1029/2001JC000825.

Fairall, C. F., E. F. Bradley, J. E. Hare, A. A. Grachev, and J. B. Edson (2003), Bulk parameterization of air-sea fluxes: Updates and verification for the COARE algorithm, J. Clim., 16, 571-591, doi:10.1175/1520-0442 (2003) $016<0571$ :BPOASF $>2.0 . \mathrm{CO} ; 2$

Fan, Y., I. Ginis, and T. Hara (2009), The effect of wind-wave-current interaction on air-sea momentum fluxes and ocean response in tropical cyclones, J. Phys. Oceanogr., 39, 1019-1034, doi:10.1175/2008JPO4066.1.

Flamant, C. (2003), Alpine lee cyclogenesis influence on air-sea heat exchanges and marine atmospheric boundary layer thermodynamics over the western Mediterranean during a Tramontane/Mistral event, J. Geophys. Res., 108(C3), 8057, doi:10.1029/2001JC001040. 
Flather, R. A. (1976), A tidal model of the north-west European continental shelf, Mem. Soc. R. Sci. Liège, 6, 141-164.

Font, J. (1990), A comparison of seasonal winds with currents on the continental slope of the Catalan Sea (Northwestern Mediterranean), J. Geophys. Res., 95(C2), 1537-1545, doi:10.1029/JC095iC02p01537.

Font, J., J. Salat, and J. Tintoré (1988), Permanent features of the circulation in the Catalan Sea, Oceanol. Acta, 9, 51-57.

Garfinkel, C. I., A. M. Molod, L. D. Oman, and I.-S. Song (2011), Improvement of the GEOS-5 AGCM upon updating the air-sea roughness parameterization, Geophys. Res. Lett., 38, L18702, doi:10.1029/ 2011 GL048802.

Gómez Lahoz, M., and J. C. Carretero Albiach (2005), Wave forecasting at the Spanish coasts, J. Atmos. Ocean Sci., 10(4), 389-405, doi:10.1080/ 17417530601127522

Hanley, K. E., S. E. Belcher, and P. P. Sullivan (2010), A global climatology of wind-wave interaction, J. Phys. Oceanogr., 40, 1263-1282, doi:10.1175/2010JPO4377.1.

Hasselmann, S., K. Hasselmann, J. H. Allender, and T. P. Barnett (1985) Computations and parameterizations of the nonlinear energy transfer in a gravity wave spectrum. Part II: Parameterizations of the nonlinear transfer for application in wave models, J. Phys. Oceanogr., 15(11) 1378-1391, doi:10.1175/1520-0485(1985)015<1378:CAPOTN >2.0.CO;2.

Hodges, K. I. (1994), A general method for tracking analysis and its application to meterological data, Mon. Weather Rev., 122, 2573-2586, doi:10.1175/1520-0493(1994)122<2573:AGMFTA>2.0.CO;2.

Hong, S.-Y., J. Dudhia, and C. H. Chen (2004), A revised approach to icemicrophysical processes for the bulk parameterization of cloud and precipitation, Mon. Weather Rev., 132, 103-120, doi:10.1175/1520-0493 (2004) $132<0103$ :ARATIM>2.0.CO;2

Janjic, Z. I. (2002), Nonsingular implementation of the Mellor-Yamada level 2.5 scheme in the NCEP Meso model, NCEP Off. Note 437 , 61 pp., Natl. Cent. for Environ. Predict., Camp Springs, Md.

Jansá, A. (1987), Distribution of the mistral: A satellite observation, Meteorol. Atmos. Phys., 36, 201-214.

Jansá, A., A. Genoves, M. A. Picornell, J. Campins, D. Radinovic, and P. Alpert (1994), Mediterranean cyclones: Subject of a WMO project, in The Life Cycle of Extratropical Cyclones, vol. 2, edited by M. A. Shapiro and S. Grønås, pp. 26-31, World Meteorol. Organ., Bergen, Norway.

Janssen, P. (2004), The Interaction of Ocean Waves and Wind, 300 pp., Cambridge Univ. Press, Cambridge, U. K., doi:10.1017/CBO9780511525018.

Janssen, P. A. E. M., and P. Viterbo (1996), Ocean waves and the atmospheric climate, J. Clim., 9, 1269-1287, doi:10.1175/1520-0442(1996) 009<1269:OWATAC $>2.0 . \mathrm{CO} ; 2$.

Janssen, P. A. E. M., P. Lionello, and L. Zambresky (1989), On the interaction of wind and waves, Philos. Trans. R. Soc. London, Ser. A, 329 , 289-301, doi:10.1098/rsta.1989.0077.

Janssen, P. A. E. M., J. D. Doyle, J. Bidlot, B. Hansen, L. Isaksen, and P. Viterbo (2002), Impact and feedback of ocean waves on the atmosphere, in Advances in Fluid Mechanics, vol. I, Atmosphere-Ocean Interactions, edited by W. Perrie, pp. 155-197, WIT Press, Southampton, U. K

Janssen, P. A. E. M., O. Saetra, C. Wettre, H. Hersbach and J. Bidlot (2004), Impact of the sea state on the atmosphere and oceans, Ann. Hydrogr., 3(772), 3.1-3.23.

Johnson, H. K., J. Hojstrup, H. J. Vested, and S. E. Larsen (1998), On the dependence of sea surface roughness on wind waves, J. Phys. Oceanogr. 28, 1702-1716, doi:10.1175/1520-0485(1998)028<1702:OTDOSS $>2.0$. $\mathrm{CO} ; 2$.

Kain, J. S. (2004), The Kain-Fritsch convective parameterization: An update, J. Appl. Meteorol., 43, 170-181, doi:10.1175/1520-0450(2004) 043<0170:TKCPAU>2.0.CO;2.

Kalnay, E., et al. (1996), The NCEP/NCAR 40-year reanalysis project, Bull. Am. Meteorol. Soc., 77(3), 437-472, doi:10.1175/1520-0477(1996) 077<0437:TNYRP $>2.0$. CO;2.

Katsafados, P., A. Papadopoulos, E. Mavromatidis, and I. Pytharoulis (2011), Numerical simulation of a deep Mediterranean storm and its sensitivity on sea surface temperature, Nat. Hazards Earth Syst. Sci., 11, 1233-1246, doi:10.5194/nhess-11-1233-2011.

Kirby, J. T., and T.-M. Chen (1989), Surface waves on vertically sheared flows: Approximate dispersion relations, J. Geophys. Res., 94, 1013-1027, doi:10.1029/JC094iC01p01013.

Komen, G. J., S. Hasselmann, and K. Hasselmann (1984), On the existence of a fully developed wind-sea spectrum, J. Phys. Oceanogr., 14 , 1271-1285, doi:10.1175/1520-0485(1984)014<1271:OTEOAF $>2.0 . C O ; 2$.

Large, W. G., and S. Pond (1981), Open ocean momentum flux measurements in moderate to strong winds, J. Phys. Oceanogr., 11(3), 324-336, doi:10.1175/1520-0485(1981)011<0324:OOMFMI>2.0.CO;2.
Larson, J., R. Jacob, and E. Ong (2005), The model coupling toolkit: A new Fortran90 toolkit for building multiphysics parallel coupled models, Int. J. High Performance Comput. Appl., 19, 277-292.

Lebeaupin Brossier, C., and P. Drobinski (2009), Numerical high-resolution air-sea coupling over the Gulf of Lions during two Tramontane/Mistral events, J. Geophys. Res., 114, D10110, doi:10.1029/2008JD011601.

Lionello, P., Dalan, F., and E. Elvini (2002), Cyclones in the Mediterranean region: The present and the doubled $\mathrm{CO}_{2}$ climate scenarios, Clim. Res., 22, 147-159, doi:10.3354/cr022147.

Lionello, P., G. Martucci, and M. Zampieri (2003), Implementation of a coupled atmosphere-wave-ocean model in the Mediterranean Sea: Sensitivity of the short time scale evolution to the air-sea coupling mechanisms, Global Atmos. Ocean Syst., 9, 65-95.

Lionello, P., J. Bhend, A. Buzzi, P. M. Della-Marta, S. Krichak, Á. A. Jans, P. Maheras, A. Sanna, I. F. Trigo, and R. Trigo (2006), Cyclones in the Mediterranean region: Climatology and effects on the environment, in Mediterranean Climate Variability, edited by P. Lionello, P. MalanotteRizzoli, and R. Boscolo, pp. 324-372, Elsevier, Amsterdam.

Madsen, O. S., Y.-K. Poon, and H. C. Graber (1988), Spectral wave attenuation by bottom friction: Theory, paper presented at 21th International Conference on Coastal Engineering, Am. Soc. of Civ. Eng., Torremolinos, Spain.

Marchesiello, P., J. C. McWilliams, and A. Shchepetkin (2001), Open boundary conditions for long-term integration of regional oceanic models, Ocean Modell., 3, 1-20, doi:10.1016/S1463-5003(00)00013-5.

Margolin, L., and P. K. Smolarkiewicz (1998), Antidiffusive velocities for multipass donor cell advection, SIAM J. Sci. Comput., 20, 907-929.

Mastenbroek, C., G. Burgares, and P. A. E. M. Janssen (1993), The dynamical coupling of a wave model and a storm surge model through the Atmospheric Boundary Layer, J. Phys. Oceanogr., 23(8), 2587-2596, doi:10.1175/1520-0485(1993)023<1856:TDCOAW>2.0.CO;2.

May, P. W., J. D. Doyle, J. Pullen, and L. David (2011), Two-way coupled atmosphere-ocean modeling of the PhilEx intensive observational period, Oceanography, 24(1), 48-57, doi:10.5670/oceanog.2011.03.

Millot, C. (1979), Wind induced upwellings in the Gulf of Lions, Oceanol. Acta, 2, 261-274.

Oddo, P., M. Adani, N. Pinardi, C. Fratianni, M. Tonani, and D. Pettenuzzo (2009), A nested Atlantic-Mediterranean Sea general circulation model for operational forecasting, Ocean Sci., 5, 461-473, doi:10.5194/os-5461-2009.

Olabarrieta, M., J. C. Warner, and N. Kumar (2011), Wave-current interaction in Willapa Bay, J. Geophys. Res., 116, C12014, doi:10.1029/ 2011JC007387.

Olabarrieta, M., J. C. Warner, B. Armstrong, J. B. Zambon, and R. He (2012), Ocean-atmosphere dynamics during Hurricane Ida and Nor'Ida: An application of the coupled ocean-atmosphere-wave-sediment transport (COAWST) modeling system, Ocean Modell., 43-44, 112-137, doi:10.1016/j.ocemod.2011.12.008.

Onken, R., A. Alvarez, V. Fernandez, G. Vizoso, G. Asterretxea, J. Tintore, P. Haley, and J. E. Nacini (2008), A forecast experiment in the Balearic Sea, J. Mar. Syst., 71(1-2), 79-98.

Perrie, W., and Y. Zhang (2001), A regional climate model coupled to ocean waves: Synoptic to multi-monthly simulations, J. Geophys. Res. 106(D16), 17,753-17,771, doi:10.1029/2001JD900207.

Pinot, J., J. Tintore, and D. Gomis (1994), Quasi-synoptic mesoscale variability in the Balearic sea, Deep Sea Res., Part I, 41, 897-914, doi:10.1016/0967-0637(94)90082-5.

Pullen, J., J. Doyle, R. Hodur, A. Ogston, J. W. Book, H. Perkins, and R. Signell (2003), Coupled ocean-atmosphere nested modeling of the Adriatic Sea during winter and spring 2001, J. Geophys. Res., 108(C10), 3320, doi:10.1029/2003JC001780.

Pullen, J., J. Doyle, and R. Signell (2006), Two-way air-sea coupling: A study of the Adriatic, Mon. Weather Rev., 134(5), 1465-1483, doi:10.1175/ MWR3137.1

Pullen, J., J. Doyle, T. Haack, C. Dorman, R. Signell, and C. Lee (2007), Bora event variability and the role of air-sea feedback, J. Geophys. Res., 112, C03S18, doi:10.1029/2006JC003726.

Pytharoulis, I., G. Craig, and S. Ballard (2000), The hurricane-like Mediterranean cyclone of January 1995, Meteorol. Appl., 7, 261-279, doi:10.1017/S1350482700001511.

Qiao, F., J. Ma, C. Xia, Y. Yang, and Y. Yuan (2006), Influence of the surface wave-induced and tidal mixing on vertical temperature structure of the Yellow and East China Seas in summer, Prog. Nat. Sci., 16(7), 739-746, doi:10.1080/10020070612330062.

Rogers, W. E., P. A. Hwang, and D. W. Wang (2003), Investigation of wave growth anddecay in the SWAN model: Three regional-scale applications, J. Phys. Oceanogr., 33, 366-389, doi:10.1175/1520-0485(2003) 033<0366:IOWGAD>2.0.CO;2. 
Ruiz, S., A. Pascual, B. Garau, Y. Faugere, A. Alvarez, and J. Tintore (2009), Mesoscale dynamics of the Balearic Front, integrating glider, ship and satellite data, J. Mar. Syst., 78, S3-S16, doi:10.1016/j.jmarsys. 2009.01.007.

Ruiz, S., L. Renault, B. Garau, and J. Tintoré (2012), Underwater glider observations and modeling of an abrupt mixing event in the upper ocean, Geophys. Res. Lett., 39, L01603, doi:10.1029/2011GL050078.

Saetra, Ø., J. Albretsen, and P. A. E. M. Janssen (2007), Sea-statedependent momentum fluxes for ocean modeling, J. Phys. Oceanogr., 37, 2714-2725, doi:10.1175/2007JPO3582.1.

Sanders, F., and J. R. Gyakum (1980), Synoptic-dynamic climatology of the "bomb," Mon. Weather Rev., 108, 1589-1606, doi:10.1175/1520-0493 (1980) $108<1589$ :SDCOT $>2.0 . C O ; 2$.

Shchepetkin, A. F., and J. C. McWilliams (1998), Quasi-monotone advection schemes based on explicit locally adaptive dissipation, Mon. Weather Rev., 126, 1541-1580, doi:10.1175/1520-0493(1998) $126<1541$ :QMASBO $>2.0 . \mathrm{CO} ; 2$.

Shchepetkin, A. F., and J. C. McWilliams (2003), A method for computing horizontal pressure-gradient force in an oceanic model with a non-aligned vertical coordinate, J. Geophys. Res., 108(C3), 3090, doi:10.1029/ 2001JC001047.

Shchepetkin, A. F., and J. C. McWilliams (2005), The regional oceanic modeling system (ROMS): A split explicit, free-surface, topographyfollowing-coordinate oceanic model, Ocean Modell., 9, 347-404, doi:10.1016/j.ocemod.2004.08.002.

Skamarock, W. C., and J. B. Klemp (2007), A time-split nonhydrostatic atmospheric model for research and NWP applications, J. Comput. Phys., 227, 3465-3485.

Skamarock, W. C., J. B. Klemp, J. Dudhia, D. O. Gill, D. M. Barker, M. Duda, X. Y. Huang, W. Wang, and J. G. Powers (2008), A Description of the Advanced Research WRF Version 3, NCAR Tech. Note NCAR/TN$475+$ STR, Natl. Cent. for Atmos. Res., Boulder, Colo.

Small, R. J., T. Campbell, J. Teixeira, S. Carniel, T. A. Smith, J. Dykes, S. Chen, and R. Allard (2011), Air-sea interaction in the Ligurian Sea Assessment of a coupled ocean-atmosphere model using in situ data from LASIE07, Mon. Weather Rev., 139, 1785-1808, doi:10.1175/ 2010MWR3431.1.

Smith, W. H. F., and D. T. Sandwell (1997), Global sea floor topography from satellite altimetry and ship depth soundings, Science, 277, 1956-1962, doi:10.1126/science.277.5334.1956.
Snyder, R. L., F. W. Dobson, J. A. Elliott, and R. B. Long (1981), Array measurement of atmospheric pressure fluctuations above surface gravity waves, J. Fluid Mech., 102, 1-59, doi:10.1017/S0022112081002528.

Trigo, I. F., T. D. Davies, and G. R. Bigg (1999), Objective climatology of cyclones in the Mediterranean region, J. Clim., 12, 1685-1696, doi:10.1175/1520-0442(1999)012<1685:OCOCIT>2.0.CO;2.

Umlauf, L., and H. Burchard (2003), A generic length-scale equation for geophysical turbulence, J. Mar. Res., 61, 235-265, doi:10.1357/ 002224003322005087.

Unden, P., et al. (2002), HIRLAM-5 scientific documentation, Tech. Rep. $S E-601-76,144$ pp., Eur. Cent. for Medium-Range Weather Forecasts, Norrköping, Sweden.

Warner, J. C., C. R. Sherwood, H. G. Arango, and R. P. Signell (2005), Performance of four turbulence closure models implemented using a generic length scale method, Ocean Modell., 8, 81-113, doi:10.1016/ j.ocemod.2003.12.003.

Warner, J. C., N. Perlin, and E. D. Skyllingstad (2008a), Using the Model Coupling Toolkit to couple earth system models, Environ. Model. Softw., 23, 1240-1249, doi:10.1016/j.envsoft.2008.03.002.

Warner, J. C., C. R. Sherwood, R. P. Signell, C. Harris, and H. G. Arango (2008b), Development of a three-dimensional, regional, coupled wave, current, and sediment-transport model, Comput. Geosci., 34, 1284-1306, doi:10.1016/j.cageo.2008.02.012.

Warner, J. C., B. Armstrong, R. He, and J. B. Zambon (2010), Development of a Coupled Ocean-Atmosphere-Wave-Sediment Transport (COAWST) modeling system, Ocean Modell., 35, 230-244, doi:10.1016/j.ocemod. 2010.07.010.

Weber, S. L., H. von Storch, P. Viterbo, and L. Zambresky (1993), Coupling an ocean wave model to an atmospheric general circulation model, Clim. Dyn., 9, 53-61, doi:10.1007/BF00210009.

Yelland, M. J., B. I. Moat, P. K. Taylor, R. W. Pascal, J. Hutchings, and V. C. Cornell (1998), Wind stress measurements from the open ocean corrected for airflow distortion by the ship, J. Phys. Oceanogr., 28 , 1511-1526, doi:10.1175/1520-0485(1998)028<1511:WSMFTO>2.0.CO;2.

Zhang, Y., and W. Perrie (2001), Feedback mechanisms for the atmosphere and ocean surface, Boundary Layer Meteorol., 100, 321-348, doi:10.1023/ A: 1018996505248 . 